Психология. Журнал Высшей школы экономики.

2016. T. 13. № 1. С. 115-153.

\title{
Cmambu
}

\section{КАУЗАЛЬНЫЙ ПЛЮРАЛИЗМ И ХОЛИЗМ В КОНЦЕПЦИИ МЕТАИНДИВИДУАЛЬНОГО МИРА}

\author{
Л.Я. ДОРФМАН \\ ${ }^{a}$ Пермский государственный институт культуры, 614000, Россия, Пермь, ул. Газеты «Звезда», Ә. 18
}

\begin{abstract}
Резюме
Представлена обновленная версия концепции метаиндивидуального мира. Она рассматривается как разновидность интегративных теорий, основана на идеях каузального плюрализма и холизма, нацелена на реконструкцию жизненного мира людей и предназначена для поиска (теоретического и эмпирического) общего и целого в нем. Целое как бы шнурует свои части в единый непротиворечивый комплекс, а полисистемный подход создает необходимые методологические ориентиры для многоаспектного ви́дения жизненного мира, показывает разнокачественность его целостности. Жизненный мир рассматривается как разнородная целость, поэтому интегративный взгляд на жизненный мир дополняется его дифференциацией. Это дифференциация обобщенных явлений как целого в контрасте к отдельным явлениям, которые нередко исследуются по отдельности и вне контекста целого. Метаиндивидуальный мир подвергается макроанализу с позиций полисистемного подхода. Выделяются две системы, система 1 и система 2, имеющие разные источники происхождения. Психологический квазикаузальный процесс развертывается в каждой из них, но в противоположных направлениях при сопоставлении систем друг с другом. Выделяются два класса психических явлений - внутри систем (гомогенные) и на их пересечении (гетерогенные, с двойными качествами). В каузальном плане, встает вопрос о том, до какой степени метаиндивидуальный мир может быть интегрированным. Так, возникает вопрос об интеграции двойных качеств психических явлений в нечто «третье» - в область, общую для обоих качеств психических явлений, или более широко - в область, общую для систем 1 и 2. В структурном плане, метаиндивидуальный мир распадается на относительно независимые домены. Выделяются четыре домена: авторство, обладание, принятие, связанность. Метаиндивидуальный мир раскрывается как многовершинная полисистема с признаками целого на ее разных уровнях.
\end{abstract}

Ключевые слова: метаиндивидуальный мир, каузальный плюрализм, полисистемный подход, психические явления с двойными качествами, целое. 


\section{Введение}

Основой интегративного тренда в психологической науке является философский принцип единства мира. Интегративные исследования способствуют производству нового психологического знания (например, на стыках его разных областей), получение которого невозможно при аналитическом подходе. В результате обнаруживается общее за границами отдельного, целое, ускользаемое из поля зрения при узком взгляде на суть вещей. Это не значит, что интегративная тенденция исключает дифференцирующую тенденцию в психологическом познании. Скорее, они дополнительны. Вместе с тем, если вторая ориентируется на поиск различий, первая, напротив, на поиск общего, выполняя роль своеобразного клея, скрепляющего разные психические явления воедино (см., напр.: Дробышева-Разумовская и др., 2015; Петровский, 2009).

Вопреки распространенным мифам, не все связано со всем. Одни психические явления взаимосвязаны, другие, напротив, не связаны между собой. Интегративные исследования основаны на поиске тех явлений, которые существуют и сами по себе, и служат «единицами» более крупного общего. В этом более крупном общем обнаруживаются феномены целостности. Их изучение обеспечивает дополнительное знание о способах существования явлений в формах интегративных качеств. С другой стороны, у отдельных психических явлений устанавливаются новые место и роль в контексте общего и целого. Положение о том, что целое больше своих частей, банально для философии. В рамках же психологической науки добывание конкретных свидетельств и фактов в пользу этого положения остается острой и актуальной проблемой.

В настоящей статье представлена обновленная версия концепции метаиндивидуального мира. Она нацелена на реконструкцию жизненного мира людей и на поиск (теоретический и эмпирический) общего и целого в нем с позиций полисистемного подхода. Целое как бы шнурует свои части в единый непротиворечивый комплекс, а полисистемный подход создает необходимые методологические ориентиры для многоаспектного ви́дения жизненного мира, показывает разнокачественность его целостности. Жизненный мир рассматривается как разнородная целость, поэтому интегративный взгляд на жизненный мир дополняется его дифференциацией. Это дифференциация обобщенных явлений как целого в контрасте к отдельным явлениям, которые нередко исследуются по отдельности и вне контекста целого.

Статья состоит из нескольких частей. В первой части концепция метаиндивидуального мира (МИМ) рассматривается как разновидность интегративных теорий. Во второй части раскрывается понятие МИМ. В третьей части описывается своеобразие применения полисистемного подхода в концепции МИМ. Четвертая часть раскрывает своеобразие систем, из которых складывается МИМ, в квазикаузальном ключе. В пятой части представлена структура МИМ. В шестой части анализу подвергается своеобразие психических явлений внутри систем 
и на их пересечении. В седьмой части внимание обращается на существование общей области в зоне пересечения систем. В восьмой части показывается МИМ как многовершинная полисистема с признаками целого. В заключении подводятся итоги выполненного исследования.

\section{Концепция МИМ мира как разновидность интегративных теорий}

Концепция МИМ (Дорфман, 1993, 2006; Dorfman, 1995) относится к классу интегративных теорий. Она основана на поиске и обнаружении общего, в то время как эмпирически ориентированные теории сосредоточены на поисках различий, носят по преимуществу частный и фрагментарный характер (об интегративных теориях см. обзор: ДробышеваРазумовская и др., 2015).

Традиционно отечественная психология придерживается целостного подхода. Его разные варианты представлены в работах К.А. Абульхановой, Б.Г. Ананьева, В.А. Барабанщикова, Б.А. Вяткина, А.А. Деркача, Б.Ф. Ломова, В.С. Мерлина, В.М. Петрова, В.А. Петровского, Я.А. Пономарева, С.Л. Рубинштейна, Е.А. Сергиенко, В.А. Толочка, М.А. Холодной, В.Д. Шадрикова. Системный подход - это своеобразное развитие философской идеи целостности с разворотом в сторону методологии науки. Системный подход открывает многоаспектное ви́дение явления и позволяет рассматривать его в нескольких системах координат (В.А. Барабанщиков, Л.Я. Дорфман, В.П. Кузьмин, Б.Ф. Ломов, Я.А. Пономарев).
Целостный (включая системный) подход образует методолого-теоретический ориентир для интегративных исследований (Абульханова, 2012; Вяткин, 2008; Деркач, Сайко, 2008; Дорфман, 2006; Мерлин, 1986; Петров, Мажуль, 2014; Петровский, 2013; Рубинштейн, 2003; Шадриков, 2013; и др.), Мы обращаем внимание, прежде всего, на теорию интегральной индивидуальности человека (Вяткин, 2015; Мерлин, 1986).

Интегративная тенденция прослеживается и в зарубежных исследованиях. Она просматривается в философии науки (см.: Корниенко, 2008). В последние годы (в отличие от прошлых лет) значимость интегративной перспективы признается и в зарубежной психологической науке (Brewer, 2013; Burgoon, Henderson, Markman, 2013; Mischel, 2009; Sternberg, 2003). К классу интегративных можно отнести, например, перспективистскую теорию (McGuire, 2004), системную теорию обоснования (Almstrom, 2006), теорию субъективного благополучия (Tay, Diener, 2011), теорию объединяющей реальности (Echterhoff, Higgins, Levine, 2009). Также следует иметь в виду развиваемые в зарубежной психологии системные теории. Они присутствуют в исследованиях личности (Magnusson, 2001; Pervin, 2001), конкретизируются в многочисленных моделях двойных систем в когнитивной и социальной психологии, психологии личности (Hofmann, Friese, Strack, 2009; Pacini, Epstein, 1999; Sowden, Pringle, Gabora, 2015).

В этот список интегративных (системных) теорий (как отечественных, так и зарубежных) входит концепция МИМ. Будучи опубликованной 
впервые более двух десятилетий назад (Дорфман, 1993), она непрерывно развивалась и подвергалась эмпирическому тестированию. Теперь она претерпела очередное обновление с позиций осмысления в ней идей каузального плюрализма и холизма.

\section{Понятие МИМ}

Понятием МИМ обозначается особый класс психических явлений, в которых их внутренняя (интракорпоральная) и внешняя (экстракорпоральная) стороны, обособление и объединение обнаруживаются в единстве. Центральное значение в понятии МИМ имеет составная часть «мета-». Прежде всего, она имеет два значения - эпистемологическое и онтологическое.

Определение «эпистемологическое» указывает на особый, метаиндивидуальный вариант полисистемного подхода (о полисистемном подходе см.: Кузьмин, 1982а, б). Понятие МИМ обозначает полисистему, которая складывается из нескольких систем, имеющих разные источники происхождения. С другой стороны, это полисистема с высокими уровнями обобщения и абстракции; она служит для описания и объяснения функционирования других, более частных систем. МИМ - это родовое общетеоретическое понятие, снабженное и дополненное частными понятиями. Под углом зрения полисистемности МИМ собирает вместе некоторое множество частных понятий, выявляя за их пределами общие особенности.

Своеобразие метаиндивидуального варианта полисистемного подхода определяется тем, как понимается и познается МИМ. Понятие МИМ возникло на пересечении теории интегральной индивидуальности Мерлина (1986), представлений о внешних, экстракорпоральных формах существования психики (Выготский, 1986), о человеке и мире (Рубинштейн, 2003), системного подхода по Кузьмину (1982a, б). Эти предпосылки наложили определенный отпечаток на объем, содержание и границы понимания МИМ. Что касается познания устройства, состава, структуры и функций МИМ, применяются исследовательские стратегии, совмещающие теоретическую рефлексию и эмпирические свидетельства. МИМ имеет некоторое множество разных значений. Их операционализация, в свою очередь, приводит к конвертации общетеоретического понятия МИМ в ряд частных, эмпирических понятий. Следовательно, подобно другим общетеоретическим понятиям (см.: Дорфман, 2012; Ушаков, 2006; Witherington, Crichton, 2007), это путь от МИМ как латентного (ненаблюдаемого) конструкта к эмпирически наблюдаемым частным конструктам. При этом эмпирические свидетельства направлены на тестирование и верификацию теоретических положений.

Онтологически МИМ представляет собой индивидуальность (личность) и ее включение в более широкие, чем она сама, системы, т.е. собственно индивидуальность (личность) и ее же выход за собственные пределы, представленность за границами своего тела (экстракорпорально) в ближнем социальном окружении. Такой взгляд на индивидуальность 
весьма тесно перекликается с идеей B.A. Петровского (Петровский, 1981a, б, 2009, 2013; Петровский, Старовойтенко, 2012; Петровский, Петровский, 1982) о личности как мультисубъектной общности, содержащей в себе интраиндивидные, интериндивидые и метаиндивидные ипостаси человека.

В обыденной жизни люди обычно полагаются скорее на субъективные представления о чем-либо, чем на объективное и точное знание. При этом субъективные представления о жизни, себе, других людях, поступках, ценностях и т.п. являются для человека более важными, чем объективно верифицируемое знание о них (Echterhoff, Higgins, Levine, 2009). МИМ складывается главным образом именно из субъективных представлений людей. Задачей познания МИМ, однако, является установление объективных закономерностей, объясняющих субъективную природу МИМ.

Индивидуальность в своем МИМ имеет две стороны. Во-первых, подразумеваются ее устойчивые (стабильные) особенности и свойства, по которым она отличается от других людей (Небылицын, 1990), например, по экстраверсии, интеллекту, способностям. Во-вторых, имеется в виду интегральная индивидуальность - иерархия разноуровневых индивидуальных свойств, объединенных в целое (Вяткин, 2015; Мерлин, 1986). Тогда встает, в частности, вопрос о самости и самобытности индивидуальности. Понятие личности примыкает к понятию индивидуальности в том смысле, что черты личности рассматриваются одним из уровней интегральной индивидуальности (Вяткин, 2015; Мерлин, 1986), носят характер устойчивых (стабильных) диспозиций (предрасположенностей), несмотря на изменчивость и вариативность ситуаций, в которых проявляет себя личность (напр.: Mischel, Shoda, 1998). Далее мы будем писать об индивидуальности, имея в виду и личность.

В ближнее социальное окружение в МИМ включается все, что является значимым для индивидуальности: родственники, друзья, субъективно ценные идеи, личные проблемы, задачи и планы, предметы быта, карьера и предпочитаемые занятия на досуге, фантазии, литературные и художественные произведения, которые открывают новые значения и смыслы в жизни индивидуальности. МИМ объединяет все это в единое целое. Но возможна и типология МИМ руководителя, инженера, учителя, студента, творца, музыкантаисполнителя, домохозяйки, ребенка и т.д. Кроме того, МИМ можно дифференцировать по разным сферам жизни и особенностям людей, которые строят, определяют границы и масштаб своего жизненного мира. В настоящей статье рассматриваются общие особенности МИМ.

\section{Полисистемный подход в концепции МИМ}

\section{Системность и детерминизм}

Понятие системы определяет не только психические явления и поведение, но и условия их функционирования и развития. Так возникают представления о единстве принципов системности и детерминизма. 
Абульханова (2000) рассматривает принцип детерминизма как проблему типа причинности, в которой гуманитарное знание ищет свою специфику, иную, чем в естественнонаучном знании. Согласно Б.Ф. Ломову (1984) и В.А. Барабанщикову (2007), детерминация раскрывается не только в каузальных отношениях, а также в общих и специальных предпосылках психических явлений, опосредующих звеньях, внешних и внутренних факторах и др.

С позиций полисистемного подхода (в контрасте к системному подходу) встает, прежде всего, вопрос о полидетерминации (в контрасте к универсальной, унитарной детерминации). Осмысление полидетерминации приводит к созданию плюралистических теорий, которые следует отличать от монистических. Монистические теории опираются либо на внутренние (напр., биологические основания личности в теории Айзенка: Айзенк, 1999; Eysenck, 1967), либо на внешние (напр., теория деятельности Леонтьева: Леонтьев А.Н., 2001) источники детерминации. Руководствуясь идеей полисистемности, плюралистические теории, напротив, направлены на поиск оснований, приводящих к выделению нескольких систем и их сосуществования, на многокачественность явлений, вызванных влиянием на них разнородных потоков детерминации.

Пожалуй, теория интегральной индивидуальности В.С. Мерлина (1986) одна из немногих в отечественной психологии, в которой предпринята успешная попытка раскрыть своеобразие свойств индивидуальности, обусловленных разно- родными потоками детерминации. Теорию В.С. Мерлина обычно описывают, делая акцент на постулируемых в ней типах детерминации - каузальном и телеологическом (напр.: Вяткин, 2015; Дорфман, 2008). Вместе с тем эта теория учитывает также внутренние и внешние источники детерминации индивидуальности.

Так, когда интегральная индивидуальность рассматривается как иерархия ее разноуровневых свойств, выделяются подсистемы свойств, обусловленные внутренними (напр., свойства темперамента) и внешними (напр., социально-психологические свойства) источниками детерминации. В свойствах интраиндивидуальности раскрываются позиции индивидуальности как действующего лица, а свойства метаиндивидуальности обнаруживаются в том, как внешний наблюдатель воспринимает и оценивает индивидуальность. Впрочем, «метабытие» индивидуальности не исчерпывается тем, как воспринимают и оценивают ее другие, но включает в себя доподлинно ее инобытие в других, «отраженную субъектность» - то, что было описано В.А. Петровским (Петровский, 1981a, б, 2013; Петровский, Петровский, 1982) как «метаиндивидная» представленность индивидуума в других людях.

В этих позициях тоже можно усмотреть выражение внутренних и внешних потоков детерминации. Индивидуальный стиль деятельности рассматривается в зависимости от свойств индивидуальности (внутренние источники детерминации) и объективных требований деятельности (внешние, социальные источники детерминации) (Вяткин, 2007, 
2008; Мерлин, 1986; Вяткин, Щукин, 2013). Рассматривая деятельность как опосредующее звено в связи разноуровневых свойств индивидуальности, В.С. Мерлин (1978) различает в деятельности ее транзитивную и системообразующую функции. В первой проявляется действие внутренних источников детерминации, во второй - внешних, социальных источников детерминации на почве возникшей новой структуры свойств индивидуальности. В.С. Мерлин рассматривает интеграцию свойств индивидуальности, с одной стороны, различая внутренние и внешние источники детерминации, с другой стороны, показывая их совместные воздействия на индивидуальные свойства.

\section{Идеи полисистемности и полидетерминации в конщепции МИМ}

Наша концепция МИМ относится к разряду плюралистических теорий. Она основана на полисистемном подходе и раскрывает полидетерминацию психических явлений в МИМ. Под углом зрения полидетерминации, концепция МИМ сближается с теорией интегральной индивидуальности В.С. Мерлина (1986), но отличается от нее тем, как рассматриваются и изучаются внутренние и внешние потоки детерминации, как они сосуществуют и взаимодействуют. Концепция МИМ несколько своеобразна и в сравнении с философской концепцией человека и мира С.Л. Рубинштейна (2003), концепцией организации и стратегии жизни К.А. Абульхановой (2000), психологическими представлениями о жизненном мире и его типологии Д.А. Леонтьева $(1992,2001)$, феноменологической концепцией мира M. Хайдеггера (Heidegger, 2005), хотя в определенной степени опирается на них. В то же время более близкой по духу концепции МИМ является концепция В.А. Петровского (1981a, б) интра-, интер- и метаиндивидуальной атрибуции бытия личности. Моя концепция сближается с концепцией В.А. Петровского по линии оппозиции «полидетерминация - универсальная (унитарная) детерминация».

\section{Внутренние и внешние источники детерминации психических явлений}

Психические явления в МИМ находятся под влиянием, прежде всего, внутренних и внешних источников детерминации.

Под внутренними источниками детерминации методологически подразумеваются телесность, психофизиологическая организация, механизмы и автоматизмы поведения человека (Леонтьев, 2000). Истоки личности в теории Г. Айзенка (1999) сводятся к биологии и наследственным факторам человека. Истоки креативности в теории Г. Айзенка (2000) опять-таки редуцируются к биологии. Вместе с тем внутренние источники детерминации могут локализоваться также в самой психике. С.Л. Рубинштейн (2003) переформулировал принцип детерминизма, признав роль внутреннего в качестве причины причинения бытия (см.: Абульханова, 2000). Такой подход оправдан в свете современных представлений об онтологическом равноправии внутреннего (психического) 
и внешнего (хотя природа психического является идеальной и субъективной) и о субъекте как источнике причинения бытия (Там же), психологической причинности (Корнилова, 2006; Корнилова, Смирнов, 2008; Леонтьев, 2011; Юревич, 2007, 2012). Свойства индивидуальности также могут выступать в роли внутренних детерминант воздействий человека на внешнее окружение (Мерлин, 1986).

Эмпирически психическое как внутреннее можно рассматривать в виде некоторой стартовой точки инициации, не обязательно генетически предопределенной, но направленной при этом на взаимодействия человека с окружающим миром (Дергачева, Дорфман, Леонтьев, 2008). Так, психические состояния и личная предрасположенность к выбору стратегии поведения в конфликтных ситуациях и попытки их разрешения раскрывают позицию субъекта (Брушлинский, 1994). Внутренняя детерминация выражается в личностных вкладах, которые одни люди производят в других людей (Петровский, 1981a, б; Петровский, Петровский, 1982), в особенностях мотивации человека. К внутренней стороне мотива относят побуждение (Мерлин, 1971), диспозицию (Martindale, 1980), интринсивный мотив (Ильин, 2002; Reiss, 2004). Если поведение основывается на собственном автономном выборе - это внутренний локус каузальности (Deci, Ryan, 2012).

Внешними источниками детерминации психического, сознания, поведения, деятельности методологически служат объективные условия существования, социальное и куль- турное окружение. В теории Л.С. Выготского (1986) употребляется понятие интериоризации - переход предметной деятельности во внутренний план сознания, формирование внутренних средств сознания из внешних средств общения. А.Н. Леонтьев (2001) объясняет происхождение сознания включением человека в социальную деятельность («внутреннее через внешнее»). Многие теории исходят из общей посылки о том, что внешними источниками детерминации личности служат социально-культурные и исторические факторы. А.Г. Асмолов (2007) подвергает анализу культурно-исторические детерминанты развития человека, социальные программы поведения. Д.А. Леонтьев (2000) пишет об интроецированных нормах, конвенциях, мнениях и ценностях авторитетных других, социальных или групповых мифах. А. Бандура (Bandura, 2002) развивает социально-когнитивную теорию личности, Дж.Г. Мид (Mead, 1934) раскрывает зависимость становления сознания и Я от общества.

Эмпирически, внешние источники детерминации выражаются в таких конструктах, как внешняя, предметная сторона мотива (Леонтьев, 1971). По внешнему критерию различают также экстринсивный мотив (Ильин, 2002; Berlyne, 1974; Friedman, Förster, 2005; James, Eisenberg, 2004), просоциальный мотив (Ильин, 2002; Barry, Wentzel, 2006), подкрепление (Baker et al., 2004; Fox et al., 2002), награду (Cameron et al., 2005; Deci, Koestner, Ryan, 1999), ожидание и привлекательность (Хекхаузен, 2001). Конечно, круг явлений, обусловленных 
внешней детерминацией, значительно шире. Они попали в поле зрения прежде всего социальной психологии - понимание, терпимость, психологическая близость, симпатия, подражание, компромисс, зависимость и др.

\section{Самодетерминация}

Современные представления о полидетерминации МИМ концептуально несколько расширились. Индивидуальность в своем мире вряд ли лишь пассивно испытывает на себе влияния потоков внутренней и внешней детерминации. Скорее всего, она как-то распоряжается ими, регулирует, контролирует, делает выбор между альтернативами. Ее активность выражается в поиске согласия и компромисса, сдерживании нежелательных внутренних и внешних влияний, сопротивлении принуждению, смене руководящих принципов поведения, переключении с одних детерминант поведения на другие (Леонтьев, 2000; Bandura, 2002; Harré, 1979).

Нередко все эти качества подводятся под понятия самодетерминации и субъектности (Абульханова, 2000; Леонтьев, 2000), а саморегуляция и самоконтроль либо присоединяются к ним (Моросанова, 2007; Осницкий, 2007), либо разводятся (Леонтьев, 2000). Мы относим саморегуляцию и самоконтроль к самодетерминации. Она может быть и субъектной (индивидуальность является автором собственных поступков), и бессубъектной (термин Абульхановой (2000)), т.е. объектной (индивидуальность вторит другим людям или попадает под власть внутренних сил, скажем, потребностей и эмоций, не выступая подлинным автором собственных поступков). Бессубъектная самодетерминация может разворачиваться ниже порогов сознания.

\section{Системы, из которых складывается МИМ}

В МИМ внутренняя детерминация инициирует одну систему его качеств (система 1), а внешняя детерминация - другую систему его качеств (система 2). Они имеют общие и специфические особенности.

\section{Общие особенности систем МИМ: квазикаузальные процессы}

В МИМ выделяются две системы на том основании, что каждую из них инициируют собственные причины. По происхождению причины в разных системах расходятся, хотя могут переплетаться в следствиях. Локус каузальности у этих систем тоже разный - интернальный и экстернальный. Еще один теоретический аргумент в пользу выделения двух систем состоит в том, что они направлены в противоположные стороны - реализация внутреннего потенциала во внешнем плане и внешнего потенциала - во внутреннем плане. Предположительно эти процессы соотносятся с разного порядка закономерностями, и потому они разводятся по разным системам. Конечно, можно ставить вопрос о том, скажем, что внутреннее «служит» внешнему - «внешнее через внутреннее», как считал С.Л. Рубинштейн (2003). Тогда вроде бы сохраняется монизм, главной остается 
одна причина, а дуальность выводится из поля анализа. Но положение о «внешнем через внутреннее» не схватывает условия, при которых внутреннее управляет внешним, а оба положения «внешнее через внутреннее» и «внутреннее, управляющее внешним» логичнее (и проще) трактовать дуально, а не сводить их к одной причине.

В МИМ каждая из систем складывается из системообразующего фактора (ядра системы) и подчиненной подсистемы (периферия системы), в каждой системе развертывается собственный (парциальный) психологический квазикаузальный процесс.

Мы употребляем термин «психологическая квазикаузальность» (а не каузальность), поскольку понятие психологической причины пока не определено в достаточной степени. Тем не менее отдельные признаки психологических причин все же обнаруживаются, они описываются ниже. Кроме того, психологические причины не существуют в единственном роде. Не следует забывать о физических, химических, биологических, социальных, культурных и другого рода причинах. Исходя из этих соображений, вводится термин «психологическая квазикаузальность».

Понятие каузального процесса ввел У. Салмон (Salmon, 1998). Он считает процесс базовой характеристикой каузальности. Определяющим признаком каузального процесса является размножение каузальных влияний. То, что происходит в одно время и в одном месте, может существенно влиять на то, что произойдет в другое время и в другом месте. Важнейшей характеристикой каузальных отношений, по У. Сал- мону, является транзитивность. Во-первых, транзитивность описывает переходы между причинами и их следствиями. Если $a$ причиняет $\sigma$, а $\sigma-8$, тогда $a$ причиняет 8 . Во-вторых, транзитивность - это свойство переноса. Скажем, информация, содержащаяся в $a$, через $\sigma$ переносится на в (Hall, 2000). В некотором смысле и с точки зрения передаваемой информации, следствие «похоже» на свою причину. В понятии транзитивности, на наш взгляд, раскрываются внутренние механизмы причинения, о котором писал С.Л. Рубинштейн (2003) и на которое обращает особое внимание К.А. Абульханова (2000).

Мы изучаем специфику систем МИМ, рассматривая их как квазикаузальные процессы. В каждой системе они развертываются от системообразующего фактора к своей подсистеме. Системообразующий фактор выступает в качестве кандидата на роль психологической причины. В плане существования (а не происхождения) подсистемы трактуются двояким образом. Во-первых, они имеют собственную специфику - свойства, которые существовали или существуют вне действия системообразующего фактора. Во-вторых, те же подсистемы, подвергшиеся изменениям под влиянием системообразующего фактора, т.е. возникшие в результате транзитивности причинения, идущей от системообразующего фактора.

\section{Специфические особенности систем МИМ}

\section{Система 1}

В упрощенном виде система 1 объединяет индивидуальность и ее 
ближнее окружение таким образом, что ядром системы 1 является индивидуальность (системообразующий фактор), а периферию этой системы образует ближнее окружение (подсистема). Индивидуальность (ее свойства или набор свойств) обладает некоторыми признаками психологической причины, а ближнее окружение (те или иные его члены) некоторыми признаками психологического следствия данной причины. Ключевым признаком системы 1 является квазикаузальный процесс с признаками транзитивности - переходом от индивидуальности (психологической причины) к ее ближнему окружению (психологическому следствию) и переносом содержания психологической причины на ее психологическое следствие. Это может приводить к тому, что второе становится «похожим» на первое, т.е. следствие уподобляется своей причине в тех или иных аспектах. Так совершается квазикаузальное «размножение».

Квазикаузальный анализ можно перевести в разряд собственно психологического анализа. Возьмем, к примеру, автономную личность. Она самостоятельно выбирает и направляет собственную активность на мир (Леонтьев, 2006).

Автономию личности можно толковать как систему, в которой системообразующим фактором выступает внутренний локус каузальности (Deci, Ryan, 2012), или самость ( «Я стараюсь сам (сама) найти выход из сложной ситуации» - один из пунктов вопросника полимодального Я, см.: Дорфман и др., 2000). Ее подсистемой будет самореализация (самоосуществление) изменения (или стремление изменить) личностью отдельных членов своего ближнего окружения («Вы говорите с другом или подругой о политике и обнаруживаете значительные разногласия. Скорее всего, вы будете настаивать на своей точке зрения и стараться сделать так, чтобы он (она) принял (приняла) ее» - один из слегка измененных пунктов каузальной шкалы, см.: Дергачева, Дорфман, Леонтьев, 2008). Личность как бы переходит за пределы своего тела, включается в ближнее окружение, трансформирует его или совершает выборы отдельных членов в нем по лекалам своей самости. Личность, так сказать, уподобляет их себе (об уподоблении см.: Толочек, 2013). Это значит, что в статусе автономной личность самореализуется (самоосуществляется) в членах ближнего окружения. В этом пункте можно вспомнить и о понятии «отраженной субъектности» (Петровский, 1985), и о его эмпирических референтах в работах И.П. Гуренковой (Петровский, Гуренкова, 1985), И.Г. Дубова (1991), А.Л. Крупенина (Крупенин, Крохина, 1995), Е.И. Кузьминой (Петровский, Кузьмина, 1988) и др.

Конечно, члены ближнего окружения могут сопротивляться давлению автономной личности, отвергать его. Тогда система 1 не возникнет, а квазикаузальный процесс будет прерван. В систему 1 также не войдут те особенности членов ближнего окружения, на которые не будет направляться транзитивность причинения автономной личностью. Это свидетельствует о том, что система 1 и квазикаузальный процесс в ней локализуются, но не приобретают всеобщего характера. 
Можно выделить несколько ключевых критериев, по которым индивидуальности может быть приписана роль системообразующего фактора и психологической причины.

1. Одно и то же психическое явление может быть следствием прежних причин и причиной новых следствий. Например, психическое состояние агрессии может быть следствием агрессивности как черты личности и в то же время причиной агрессивного поведения (Дорфман, 2014б). В МИМ включается участок каузальной цепи (в целом она состоит из множества звеньев), в котором происхождение индивидуальности «вырезается» из поля анализа (ее роль следствия к прежним причинам). Но сама она трактуется как исходный пункт квазикаузального процесса, психологическая причина, причиняющая изменения в подсистеме своей системы.

2. Концепция МИМ опирается прежде всего на изучение ближних (проксимальных) причин, а не отдаленных (дистальных) и предельных (как в метафизике). Ближней является причина, которая темпорально близка к произведенному ею результату, в отличие от филогенетических причин, онтогенетических причин, причин, коренящихся в обществе и культуре, хотя последние (дистальные или предельные) порой трактуются весьма жестко, как только «реальные» причины (Дорфман, 2014a, б; Alessi, 1992).

3. Действие индивидуальности как психологической причины начинается до наступления изменений, которые она же производит в своем ближнем окружении, т.е. соблюдается каузальный принцип темпораль- ной асимметрии. Через какое-то время характер темпоральных отношений причины и следствия может измениться. Изменения состоят в том, что с наступлением следствия действие причины не прекращается, a продолжается. В этом общем интервале времени у них складываются отношения темпоральной симметрии (см.: Дорфман, 2014б; Hausman, 1998; Salmon, 1998). Причина не остается в прошлом, ее действие продолжается в настоящем. Следствия не отрываются от причины и не убегают в будущее. Временна́я дистанция отсутствует, они действуют одновременно. Причина существует континуально, а ее следствия могут быть дискретными, повторяться или на смену одним следствиям могут приходить другие. Таким образом, психологические причины и их следствия вначале действуют последовательно, асимметрично, а затем могут действовать одновременно, симметрично.

Склонность к поиску ощущений (Zuckerman, 2007) может быть следствием прежних причин оптимального уровня активности катехоламинной системы, включающей допамин и норадреналин, ретикулярной активирующей системы, оптимального уровня кортикального бодрствования. Вместе с тем склонность к поиску ощущений, закрепленную в черте личности, можно рассматривать и с другой стороны как ближнюю причину поведения, которое характеризуется вариативностью, направлено на поиск новизны, выражает готовность к физическим, социальным, правовым и финансовым рискам. Это поиски впечатлений и приключений, переживаний и нового 
опыта, растормаживания и избегания скуки. Очевидно, что такого рода поиски могут влиять на широту круга общения в ближнем окружении, провоцировать относительное снижение продолжительности межличностных отношений с партнером, частую смену партнеров. Склонность к поиску ощущений (ближняя причина) существует как черта личности латентно, стабильно и надситуативно, предшествует наступлению изменений, которые личность производит в своем ближнем окружении (темпоральная асимметрия). Но эта склонность не исчезает, сохраняется и продолжается, когда поиски впечатлений и приключений, переживаний и нового опыта, растормаживания и избегания скуки переходят на уровень поступков. В эти периоды времени и склонность к поиску ощущений как черта личности, и склонность к поиску ощущений как поведение проявляются одновременно (темпоральная симметрия).

Главный смысл таких изменений в ближнем окружении мы находим в уподоблении (об уподоблении см.: Толочек, 2013). Индивидуальность стремится оставлять психологические следы своего Я в членах ближнего окружения, уподобляя их (в тех или иных аспектах) себе. Если же члены ближнего окружения не отвечают «задаче» уподобления, они подвергаются трансформации или, по меньшей мере, индивидуальность стремится их изменять, все же уподобляя себе. Так, в системе 1 ближнее окружение в каких-то аспектах становится производным от индивидуальности. Иначе говоря, в системе 1 индивидуальность занимает первичную позицию (неизменность ее стремлений), а ближнее окружение - вторичную (его изменчивость и податливость устремлениям индивидуальности).

\section{Система 2}

Система 2 тоже объединяет индивидуальность и ее ближнее окружение, но их отношения оборачиваются в сравнении с отношениями в системе 1. В упрощенном виде система 2 объединяет индивидуальность и ее ближнее окружение таким образом, что ядром системы 2 является ближнее окружение (системообразующий фактор), а на периферию этой системы попадает индивидуальность (подсистема). Теперь у ближнего окружения (тех или иных его членов) обнаруживаются некоторые признаки психологической причины, а у индивидуальности (ее свойств или набора свойств) некоторые признаки изменений в силу воздействия на нее данной причины. Опять-таки ключевым признаком системы 2 является квазикаузальный процесс с признаками транзитивности перехода от ближнего окружения (психологической причины) к индивидуальности (психологическому следствию) и переноса содержания психологической причины на ее психологическое следствие. И вновь это может приводить к тому, что второе становится «похожим» на первое, т.е. следствие уподобляется своей причине в тех или иных аспектах. Так совершается квазикаузальное «размножение» в системе 2 , но в другом, противоположном направлении, чем в системе 1.

Перевод квазикаузального анализа в разряд собственно психологического 
позволяет раскрывать отношения внутри системы 2. Рассмотрим локус каузальности. Если поведение индивидуальности основывается на внешних требованиях или ожидаемой награде, это внешняя каузальная ориентация, тип мотивации с соответствующими когнитивными, аффективными и другими характеристиками индивидуальности (Deci, Ryan, 2012). В каузальной шкале (Дергачева, Дорфман, Леонтьев, 2008) есть такой пункт (слегка изменен): «Вы выбираете подарок другу на день рождения. Тогда вы постараетесь косвенным путем узнать, чего бы ему хотелось получить». Системообразующим фактором здесь выступает внешний локус каузальности. Его подсистемой может быть зависимая позиция, которую принимает личность по отношению к внешним воздействиям. Скажем, «Порой друзья используют меня в своих целях» один из пунктов вопросника полимодального Я, иллюстрирующего зависимость (Дорфман и др., 2000).

Конечно, индивидуальность может сопротивляться внешнему воздействию, отвергать его или избегать. Тогда система 2 не возникнет, а квазикаузальный процесс будет прерван. В систему 2 также не войдут те особенности индивидуальности, на которые не будет направляться транзитивность причинения ближним окружением. Значит, система 2 и квазикаузальный процесс в ней локализуются, но не приобретают всеобщего характера.

Ближнему окружению отводится роль системообразующего фактора и психологической причины в системе 2 по тем же критериям, по которым определяются системообразующий фактор и психологическая причина в системе 1. Во-первых, поведение членов внешнего окружения может быть следствием действия прежних причин и причиной новых следствий. Однако поведение членов внешнего окружения рассматривается как исходная причина изменений индивидуальности. Во-вторых, воздействия внешнего окружения на индивидуальность ограничиваются ближними (проксимальными) причинами, отвлекаясь от действия отдаленных и предельных причин. В-третьих, действия ближнего окружения на индивидуальность изучаются в формате темпоральной асимметрии и симметрии.

\section{Как индивидуальность и ее ближнее окружение включаются в системы МИМ}

Чтобы избежать противоречий, нужно уточнить, как индивидуальность и ее ближнее окружение могут распределяться по системам 1 и 2. Эта загадка того же ряда, что и загадка о том, как одна и та же точка может относиться к двум прямым. У. Джеймс отмечал, что «такое возможно, если точка находится на их пересечении» (James, 1904/1976, p. 8). Точка на пересечении двух прямых - это метафорическое выражение индивидуальности, распределенной по системам 1 и 2, т.е. в разных «местах», «здесь» и «там». Точка на пересечении двух прямых - это также метафорическое выражение ближнего окружения, распределенного по системам 1 и 2.

Действительно, индивидуальность и ее ближнее окружение объединяются в каждой системе своеобразно и 
выполняют при этом разные функции. В системе 1 индивидуальность управляет ближним окружением, а в системе 2, наоборот, ближнее окружение управляет индивидуальностью. Каузально, системы 1 и 2 разворачиваются в противоположных направлениях. В структурном же плане, индивидуальность и ее ближнее окружение включаются в системы 1 и 2 своими разными сторонами. Поэтому структурно они также разводятся. Значит, индивидуальность и ее ближнее окружение своими разными сторонами расходятся по системам 1 и 2 и не смешиваются.

Обычно психологи изучают какие-либо явления в рамках либо системы 1, либо системы 2. Благодаря этому логические столкновения между ними затушевываются, уходят в тень. Но если в поле исследовательского внимания удерживать обе системы одновременно, легко заметить, что они могут как «мирно» сосуществовать, так и конфликтовать между собой. Скажем, в своем МИМ одна и та же индивидуальность может быть и неизменной (в системе 1), и изменчивой (в системе 2). В этом можно усмотреть внутренний конфликт, вызванный включением индивидуальности в системы 1 и 2 своими разными сторонами. С другой стороны, системы 1 и 2 могут соотноситься по принципу дополнительности (о системном принципе дополнительности см.: Блауберг, Садовский, Юдин, 1970; Блауберг, Юдин, 1973; Avital, 2003), разрешая возможный конфликт между системами.

Следующие примеры иллюстрируют сосуществование систем 1 и 2 как дополнительных. Представьте человека, выбирающего книгу для чтения. В этом случае читатель занимает первичную позицию, а отобранная книга - вторичную (система 1). Когда читатель усваивает содержание книги, он попадает под ее влияние. Значит, книга занимает первичную позицию, а ее читатель - вторичную (система 2). Эти отношения дополнительны, а не конфликтны. Более сложный пример возникает, если представить, что читатель и попадает под влияние содержания книги (система 2), и в то же время ментально изменяет, субъективно модифицирует и привносит дополнительные значения и смыслы в содержание книги (система 1). Такая ситуация даже более правдоподобна, если совместно рассматривается, как человек вовлекается в процесс научения писать стихи (система 2), а затем начинает сочинять их сам (система 1). Любой из этих примеров показывает роль не одной, а обеих систем, и они дополняют друг друга. Конечно, эти иллюстрации носят весьма упрощенный характер, но они раскрывают суть метаиндивидуального подхода. Он обеспечивает приращение нового знания об особенностях МИМ, поскольку во внимание принимается не какая-либо одна система (как при монистическом подходе), а обе системы одновременно. Это новое знание умножает наши представления о природе МИМ с позиций двойственности источников его детерминации и двойных систем, из которых он складывается.

Положение о двойных системах в МИМ подкрепляется не только здравыми рассуждениями. Оно получает также эмпирическую поддержку. 
Первая и ближайшая исследовательская задача состоит, в частности, в том, чтобы получить эмпирический ответ на следующий вопрос: можно ли системы 1 и 2 отделять друг от друга и в то же время устанавливать их отношения между собой? На уровне переменных ответ на этот вопрос подразумевает различение переменных в системах 1 и 2: либо по составу, либо по степени их выраженности. Конечно, этими ответами вопрос о двойственности МИМ эмпирически не исчерпывается. Вместе с тем это хорошее начало для разработки данного вопроса. Несколько эмпирических исследований было проведено, в них предлагалась оригинальная процедура определения двойственности.

В исследовании, которое выполнила Е.В. Старцева под моим руководством (см.: Дорфман, 2010), девушек в возрасте от 18 до 20 лет просили оценить своих матерей, отцов, младших сиблингов и себя по ряду переменных. Предполагалось, что девушки в роли дочерей (система 2) и те же девушки в роли старших сестер (система 1) оценивают себя по-разному по одним и тем же переменным. Результаты исследования свидетельствовали о значимых различиях между этими ролями девушек по переменным Я-концепции, поиска новизны, доминантности. Значимыми дискриминаторами также были переменные контроля над другими людьми, зависимости от награды, избегания неприятности, упорства, готовности к приспособлению и сотрудничеству. Значит, эти переменные характеризовались подвижностью и способностью к смещениям в зависимости от тех ролей, которые исполняли девушки. В более широком плане полученные данные свидетельствуют о том, что указанные переменные изменяются в зависимости от включения их в систему 1 или 2, т.е. феномен двойственности является довольно глубоким и может проникать на уровень переменных.

В другом исследовании (Дорфман, Савинкин, 2012) изучались отношения сержантов (мужчин) с офицерами и курсантами в военном институте внутренних войск РФ. Опять-таки предполагалось, что оценки сержантами офицеров (в условиях субординации - система 2) и оценки теми же сержантами курсантов (в условиях командования - система 1) различаются по одним и тем же переменным. Действительно, значимые различия обнаруживались по переменным доминантности, социальной конформности, лжи, самодоверия. Полученные данные свидетельствуют о том, что указанные переменные изменяются в зависимости от включения их в систему 1 или 2, т.е. характеризуются двойственностью.

\section{Структура МИМ}

Полисистемный подход служит основой развития концепции МИМ и в структурном ключе.

Как уже отмечалось, квазикаузальные процессы в системах 1 и 2 разворачиваются в противоположных направлениях. Индивидуальность занимает первичную позицию в системе 1 (системообразующий фактор), но вторичную позицию (подсистема) в системе 2. Ближнее окружение занимает первичную позицию в системе 2 (системообразующий 
фактор), но вторичную позицию (подсистема) в системе 1. С другой стороны, внутри каждой системы индивидуальность и ее ближнее окружение также занимают противоположные позиции друг к другу. В системе 1 индивидуальность занимает первичную позицию, а ее ближнее окружение - вторичную. В системе 2, наоборот, индивидуальность занимает вторичную позицию, а ее ближнее окружение - первичную. Такие различия между системами и внутри систем возникают в силу того, что у них противоположные источники детерминации: внутренние причины действуют в системе 1 и внешние причины - в системе 2.

Отсюда появляются представления о том, что в МИМ индивидуальность и ее ближнее окружение характеризуются многомерностью. Системы 1 и 2 относятся к разным измерениям МИМ потому, что они являются разнопорядковыми. Подразумевается разнопорядковость не в плане величин, которые могут быть выражены числом или разным типом величин, подобно весу и температуре. Имеются в виду качественные различия их особенностей, производных от разных источников детерминации. Это может выражаться в том, что психические явления внутри систем являются скорее «похожими», а относящиеся к разным системам - скорее несходными и в большей степени различными. Отсюда представления о том, что системы 1 и 2 придают МИМ многомерность и разномерность.

Далее встает вопрос о подызмерениях. Область индивидуальности распадается на два подызмерения в связи с тем, что она входит в системы
1 и 2, выполняя противоположные функции - первичную в системе 1 и вторичную в системе 2. Область ближнего окружения тоже распадается на два подызмерения, поскольку она входит в системы 1 и 2, выполняя противоположные функции - первичную в системе 2 и вторичную в системе 1.

В конечном итоге встает вопрос о многомерном устройстве МИМ: два измерения существуют в виде систем 1 и 2, два подызмерения индивидуальности в силу ее включения в системы 1 и 2, два подызмерения ближнего окружения опять-таки потому, что оно входит в системы 1 и 2.

В наиболее простом варианте, МИМ организован четырехмерно, что приводит к выделению в нем четырех относительно самостоятельных доменов.

Первым является домен авторства - первичная позиция индивидуальности в системе 1. Авторство есть склонность индивидуальности действовать самостоятельно и производить свободные выборы по внутренним (собственным) основаниям. Индивидуальность руководствуется тем, что она является причиной поступков, которые она совершает, и результатов, к которым она приходит (самопричинение). При этом индивидуальность проводит различия между результатами собственных действий и результатами, которые достигают другие люди (Петровский, 1997; van der Weiden, Ruys, Aarts, 2013).

Вторым является домен психологического обладания - вторичная позиция ближнего окружения в системе 1. Склонность к психологическому обладанию - это выход 
индивидуальности за собственные пределы, стремление (и его реализация насколько возможно) владеть кем-либо или чем-либо как своей собственностью. Индивидуальность реализует склонность к обладанию, обращаясь к ближнему окружению, отношениям с близкими людьми, предметам быта или субъективно ценным идеям. Ближнее окружение при этом претерпевает те или иные изменения, в которых запечатлеваются следы вмешательства индивидуальности. В результате ближнее окружение (или его отдельные члены) становится «моим», это «мое» (Дорфман, 2004; Pierce, Kostova, Dirks, 2003).

Третий домен обозначается как принятие - первичная позиция ближнего окружения в системе 2. Принятие - это тоже выход за собственные пределы, но иначе, чем во втором домене. Принятие - это переход индивидуальности в позицию внешнего окружения, ее склонность принимать внешнее окружение таким, какое оно есть и существует. Индивидуальность при этом принимает роль кого-то или чего-то из своего ближнего окружения (Mead, 1934). Она оценивает ситуации, состояния или предметы глазами близких людей - воспринимая, познавая, принимая их намерения, цели и относясь к ним (напр.: Echterhoff, Higgins, Levine, 2009).

Четвертый домен обозначается как связанность - вторичная позиция индивидуальности в системе 2 . В отличие от психоанализа, в котором этот термин обозначает, в частности, операцию, направленную на ограничение свободного движения возбуждений или на связывание представлений друг с другом, мы употребляем это понятие в другом значении. Имеется в виду склонность индивидуальности тяготеть к другим людям, устанавливать отношения и объединяться с ними (Deci, Ryan, 2012). Для описания различных аспектов связанности индивидуальности используются такие термины, как «часть социума», «Я в отношениях с Другим», «необусловленное и неинструментальное стремление слиться с Другим», «зависимость», «чувство принадлежности», «привязанность», «присоединение», «кооперация», «близость» (Blatt, 2008). Ранее мы обозначали область связанности терминами зависимости, а затем конформности и референтности (Дорфман, 2007).

Таким образом, в МИМ область индивидуальности распадается на домены авторства и связанности, ближнее окружение - на домены обладания и принятия. При этом домены авторства и обладания совместно характеризуют систему 1, а домены принятия и связанности совместно - систему 2. Эмпирические свидетельства поддерживают теоретические представления о четырехмерном устройстве МИМ (Дорфман, Зубакин, 2008; Dorfman, Ogorodnikova, 2007).

\section{Психические явления внутри систем и на их пересечении}

В структурном плане МИМ распадается на относительно независимые домены (см. предыдущий параграф). В каузальном же плане встает вопрос о том, до какой степени МИМ может быть интегрированным. При такой постановке вопроса в анализ 
включаются два режима функционирования систем 1 и 2: параллельный и пересекающийся. При каких условиях вступает в действие тот или иной режим, пока не ясно, но можно попытаться приблизиться к пониманию параллельности и пересекаемости систем в МИМ. Этот вопрос является важным не только в аспекте изучения и понимания особенностей функционирования систем, но и в аспекте анализа психических явлений внутри систем и на их пересечении.

\section{Параллельньй режим}

Как известно, в евклидовой геометрии параллельными называют прямые, которые лежат в одной плоскости и не пересекаются. Употребляя термин параллельности, мы имеем в виду тот случай, когда системы 1 и 2 не пересекаются и лежат в разных плоскостях. Непересечение - это раздельное существование систем 1 и 2 по их происхождению: внутренних источников детерминации системы 1 и внешних источников детерминации системы 2. Разные источники детерминации локализуются в разных «местах» и имеют разную природу. Соответственно внутренние (в системе 1) и внешние (в системе 2) психологические причины тоже расходятся, а квазикаузальные процессы имеют разные источники и противоположные направления.

C этих позиций психические явления внутри каждой системы можно трактовать как гомогенные, или однокачественные, по критерию их происхождения. Скажем, понятие мотива как побуждения является гомогенным (однокачественным) в смысле его общего (внутреннего) источника происхождения. Понятие мотива как предмета тоже является гомогенным (однокачественным), но в смысле его общего (внешнего) источника происхождения.

Конечно, в МИМ между системами 1 и 2 могут быть переходы, возникать взаимосвязи и взаимодействия, скажем, в формах координации или конфликта. Они могут находиться в состоянии согласия, компромисса или соперничества за преобладание в МИМ. Все эти примеры, однако, не отменяют тот факт, что исходно системы 1 и 2 функционируют независимо и параллельно, а психические явления в каждой из них сохраняют гомогенность.

\section{Режим пересечения}

С.Л. Рубинштейн (2003) исходил из того, что существуют особые «точки», некое общее пространство, в котором разные причины перекрещиваются. Вспомним вновь геометрическую метафору У. Джеймса (James, 1904/1976): две прямые исходно независимы, но точка их пересечения относится как к одной, так и к другой прямой. Теперь метафора У. Джеймса иллюстрирует не столько расхождения психических явлений по системам 1 и 2, сколько возможность их пересечения. Системы 1 и 2 (и психические явления в них) могут пересекаться, несмотря на то, что остаются независимыми по происхождению и направлению квазикаузальных процессов в них.

Как можно понимать пересечение систем 1 и 2? Пересекаясь, они не сливаются, но в каких-то аспектах, 
возможно, перекрывают друг друга. Тогда появляется зона взаимного покрытия, и она может иметь особенности, общие для систем 1 и 2. Базовое предположение состоит в том, что в зоне взаимного покрытия системы 1 и 2 имеют некоторую область общего. В связи с этим встает также вопрос об особом классе психических явлений, находящихся на пересечении обеих систем и испытывающих на себе их совместные воздействия. Такого рода явления можно обозначить (по происхождению) как гетерогеннье, или с двойными качествами. Понимание мотива, взятого в рамках системы 1 (побуждение) и системы 2 (предмет) совместно, приводит к его толкованию как психического явления с двойными качествами. Более того, не исключено, что разные стороны мотива (побуждение и предмет) в какой-то степени стыкуются, и в зоне их взаимного покрытия открываются особенности, общие для понимания мотива и как побуждения, и как предмета. Это «третье» значение мотива. Оно является более общим (в сравнении с его отдельными сторонами) и интегральным. «Третье» значение мотива обнаруживается при условии, что он рассматривается как психическое явление с двойными качествами.

В примере с мотивом выражается положение о двойственности качественной определенности источников детерминации, появляющихся на их основе двойных системах и психических явлениях с двойными качествами в МИМ. Существенно, что возможен перевод данного положения в план эмпирических исследований. Так, можно строить модели, основанные на оценивании совместных воздействий факторов внутренней и внешней детерминации (или производных от них конструктов) на одно и то же психическое явление с помощью линейных структурных уравнений. Если обнаруживаются значимые вклады факторов внутренней и внешней детерминации в одно и то же психическое явление, значит, последнее можно толковать как имеющее в какой-то степени двойные качества.

Метаиндивидуальные схемы исследования могут носить, конечно, и более сложный характер. Так, в модель могут включаться не одно, а несколько психических явлений, скажем, креативное мышление и вера в интуицию (Дорфман, Бутакова, 2015). При этом тестируется роль опосредующих звеньев между ними. Рассматриваются коррелирующие и не коррелирующие вклады факторов внутренней и внешней детерминации в психическое явление. Действия факторов внутренней и внешней детерминации на психическое явление могут изучаться не только одновременно, но и последовательно, в том числе с учетом кольцевых взаимодействий этих факторов (о кольцевых зависимостях между психическими свойствами и деятельностью человека см.: Мерлин, 1978; Рубинштейн, 2003). Еще более сложной является модель, в которой изменения психических явлений рассматриваются как результат действия факторов внутренней и внешней детерминации, развертывающихся в цепи (двойные цепи) с включением ряда опосредующих звеньев.

Положение о психических явлениях с двойными качествами 
неоднократно подвергалось эмпирическому тестированию на различном материале. Установлено, что к психическим явлениям с двойными качествами можно отнести Я-концепцию как полимодальное Я (Дорфман, 2004), креативное мышление (Дорфман, 2007), эмоциональные предпочтения (Дорфман, 1997; Дорфман, Токарева, 2013), дисциплинированность (Дорфман, Лядов, 2015).

\section{Общая область систем}

Тема пересечения систем 1 и 2 неизбежно приводит к постановке вопроса об интеграции двойных качеств психических явлений в нечто «третье» - в область, общую для обоих качеств психических явлений, или более широко - в область, общую для систем 1 и 2. Обычно такого класса задачи решаются путем установления взаимосвязей переменных с помощью корреляционного, факторного анализов, многомерного шкалирования и т.п. Так устанавливается только внутренняя структура общего. Собственно же общее для систем 1 и 2, так сказать, его (общего) внешняя структура, остается нераскрытой, в подтексте скорее полагается, чем прямо измеряется (см.: Дорфман, 2015).

Проблема начинается с того, как понимать общее, как его операционализировать, измерять и представить общее у нескольких переменных в виде отдельной количественной переменной.

Следуя И. Канту (2006), можно сказать, что общее - это то, что сходно у систем 1 и 2, при этом они остаются разными и продолжают существовать по отдельности. Мы обращаем внимание на формальнологический закон обратного соответствия между содержанием и объемом понятия. Общее имеет больший объем, чем частное. Это значит, что объем общего у систем 1 и 2, взятых совместно, должен быть больше объема систем 1 и 2, взятых по отдельности.

В эмпирическом плане, общее это область пересечения переменных систем 1 и 2 («общие» переменные), а частное образуют области, в которых переменные систем 1 и 2 не пересекаются («дискриминантные» переменные). «Общие» и «дискриминантные» переменные не смешиваются, а разводятся на две разные подгруппы. Объем понятия общего у переменных систем 1 и 2, взятых совместно, должен быть больше понятия объема переменных систем 1 и 2, взятых по отдельности. Заметим, что речь идет не о корреляциях переменных. Корреляция, как известно, выражает степень сопряженных изменений переменных. Это мера их связи, но не обязательно их сходства. Корреляции не дают ответа на вопрос о подобии переменных, о том, что́ у них общее. Кроме того, нужно иметь в виду, что в разных контекстах понятия «общих» и «дискриминантных» переменных могут меняться местами, т.е. они являются относительными и имеют смысл при сопоставлении друг с другом в определенном концептуальном ключе.

Можно ли операционализировать понятия «общих» и «дискриминантных» переменных у систем 1 и 2? Мы предлагаем использовать для этого критерий вариативности (о вариативности см.: Дорфман, Балева, 2014). Размах вариативности может 
служить маркером понятия объема переменных. Чем выше размах вариативности между переменными, тем более вероятно, что они составляют общую область пересечения систем 1 и 2. И наоборот, у переменных, относящихся к каждой системе по отдельности («дискриминантных» переменных), размах вариативности должен быть меньше размаха вариативности «общих» переменных. Пожалуй, В. Штерн (1998) был первым, кто попытался связать общее с размахом вариативности. Но он не довел свой замысел до уровня эмпирической верификации.

Мы попытались восполнить образовавшийся здесь пробел в рамках концепции МИМ и путем применения специальной процедуры. В результате ряда пилотажных исследований был установлен один из возможных алгоритмов определения «общих» и «дискриминантных» переменных.

(1) C позиций определенной концепции (или нескольких концепций) ставится задача выделить из заданного набора «общие» и «дискриминантные» переменные.

(2) Отобранные переменные подвергаются эксплораторному однофакторному анализу. Он позволяет эмпирически выразить идею общего в терминах фактора и доли объяснимой дисперсии, которая падает на него. Попутно заметим, что понятие фактора - это объяснительный конструкт; его невозможно конвертировать в количественную переменную для применения в статистических расчетах совместно с иными количественными переменными.

(3) В поисках наибольшего размаxa вариативности выделяются несколько переменных с высокими факторными весами и несколько переменных с низкими факторными весами. Переменные должны относиться как к системе 1, так и к системе 2. Затем оценивается размах вариативности между соответствующими переменными. Высокие и низкие факторные веса указывают на переменные, размах вариативности между которыми полагается наиболее широким («общие» переменные). Размах вариативности между переменными со средними факторными весами полагается более узким («дискриминантные» переменные).

(4) Размах вариативности переменных оценивается с использованием стандартных отклонений (по строкам, а не столбцам); затем создаются новые переменные, составленные из индивидуальных значений стандартных отклонений.

(5) Переменные систем 1 и 2, между которыми бо́льший размах вариативности (в сравнении с переменными, между которыми меньший размах вариативности), являются кандидатами на роль «общих» переменных. Они характеризуют область пересечения систем 1 и 2. «Дискриминантными» (относящимися к каждой системе по отдельности) являются переменные, между которыми размах вариативности меньше, чем размах вариативности «общих» переменных. Верификация «общих» и «дискриминантных» переменных опять-таки производится по вариативности. Ее размах должен быть статистически бо́льшим у «общих» переменных, чем у «дискриминантных» переменных. В случае же отсутствия значимых различий между ними нет оснований выделять и различать 
«общие» и «дискриминантные» переменные.

Удивление может вызвать бо́льшее сходство «дискриминантных» переменных (вариативность у́же) в сравнении с различиями, более выраженными у «общих» переменных (вариативность шире). В рамках нашего подхода сужение вариативности «дискриминантных» переменных указывает на их локальность, поскольку они образуют «узкие» подгруппы в силу отношения либо к системе 1, либо к системе 2. Широкий размах между «общими» переменными, наоборот, свидетельствует об их более крупном масштабе в сравнении с размахом «дискриминантных» переменных, поскольку «общие» переменные пересекают системы 1 и 2.

Размах вариативности «общих» переменных сравнивался с размахом вариативности «дискриминантных» переменных на материале Я-концепции (полимодального Я) и дисциплинированности. Было установлено, что субмодальности Я могут рассматриваться как своеобразные проекции систем 1 и 2 в МИМ (Дорфман, Зубакин, 2008). В то же время размах вариативности переменных полимодального Я в целом («общие» переменные) был значимо больше размаха вариативности переменных ее отдельных субмодальностей («дискриминантные» переменные). Этот результат можно рассматривать как эмпирическое свидетельство в пользу того, что общей областью пересечения систем 1 и 2 может служить полимодальное Я в целом. С помощью структурных линейных уравнений были установлены значимые вклады «общих» переменных в «дискриминантные» переменные как системы 1, так и системы 2 (Дорфман, 2016). Эти результаты поддерживают наши представления о том, что общая область пересечения включает переменные обеих систем и может влиять на переменные, относящиеся к каждой системе по отдельности. На материале дисциплинированности были получены сходные данные. Были выделены социальная, самодисциплинированность, общая дисциплинированность. По критерию вариативности в социальную дисциплинированность вошли переменные ориентации на результат и социальных мотивов («дискриминантные» переменные), в самодисциплинированность - переменные принятия ответственности на себя и осмысленности («дискриминантные» переменные), в общую дисциплинированность - переменные сознательности, строгости к себе и послушания с детства («общие» переменные). Опять-таки, были установлены значимые вклады переменных общей дисциплинированности в переменные самодисциплинированности и социальной дисциплинированности (Дорфман, Лядов, 2015). И вновь эти результаты поддерживают наши представления о том, что общая область пересечения включает переменные обеих систем и может влиять на переменные, относящиеся к каждой системе по отдельности.

Как можно понимать общую область пересечения систем 1 и 2 в терминах каузальности? Предположительно «общие» переменные указывают на их потенциал выступать кандидатами на роль факторов самодетерминации. Ее задача просматривается в 
том, чтобы регулировать и контролировать действия внутренних и внешних причин. Действительно, благодаря общей области индивидуальность может обеспечивать интеграцию и координацию функционирования систем 1 и 2, включая сдерживание или усиление одной из них или обеих.

\section{Вершины целого}

Общая область пересечения систем 1 и 2 анализировалась в предыдущем параграфе. Действительно, эмпирические данные поддерживают идею пересечения систем 1 и 2 и существование общей области в зоне их пересечения.

Вместе с тем можно предположить, что подызмерения систем 1 и 2 также пересекаются, т.е. имеют общие области. В качестве подызмерений индивидуальности были выделены домены авторства (относится к системе 1) и связанности (относится к системе 2). Мы предсказываем наличие у них общей области. Возможно, авторство и связанность объединяются в составе чего-то более крупного и общего на правах его отдельных компонентов. Скорее всего, это будет психическое явление (или явления) с двойными качествами. Пока вопрос о таком общем явлении остается открытым.

Кроме того, в качестве подызмерений ближнего окружения были выделены домены принятия (относится к системе 2) и обладания (относится к системе 1). Опять-таки, мы предсказываем наличие у них общей области. Возможно, принятие и обладание объединяются в составе чего-то более крупного и общего на правах его отдельных компонентов.
И вновь, скорее всего, это будет психическое явление (или явления) с двойными качествами. Пока вопрос о таком общем явлении тоже остается открытым.

Таким образом, речь может идти об общих областях на пересечении систем 1 и 2, а также об общих областях, по меньшей мере, для доменов индивидуальности и доменов ближнего окружения.

На наш взгляд, можно осуществить переход от понятия общего к понятию целого. Эти три общие области можно рассматривать маркерами целого. Оно классифицируется по локусу, уровням обобщения и абстракции. Наиболее крупным является целое, которое собирает вместе и объединяет системы 1 и 2. Целое здесь характеризует МИМ как таковой. Обозначим его термином «МИМ как целое». На более низких уровнях обобщения и абстракции обнаруживается целое, которое собирает вместе и объединяет подызмерения индивидуальности - домены авторства и связанности. Обозначим его термином «индивидуальность как целое». В свою очередь, на противоположном полюсе МИМ появляется целое, которое собирает вместе и объединяет подызмерения ближнего окружения - домены принятия и обладания. Обозначим его термином «ближнее окружение как целое».

Судя по всему, целое можно разложить на уровни. Наиболее высоким является уровень МИМ как целого (высокая степень обобщения и абстракции), а более низкими являются уровни индивидуальности как целого и ближнего окружения как целого (менее высокая степень обобщения и абстракции). Каждая 
разновидность целого вносит свой вклад в интеграцию МИМ. Полную же его интеграцию совместно обеспечивают все разновидности целого.

В конечном итоге МИМ можно представить как многовершинную полисистему, в которой человек в своем МИМ как целом способен переключаться с индивидуальности как целого на ближнее окружение как целое и в обратном направлении. Это может быть связано с самодетерминацией (ср.: Harré, 1979).

\section{Заключение}

Понятием МИМ описывается особый класс психических явлений, в которых их внутренняя (интракорпоральная) и внешняя (экстракорпоральная) стороны, обособление и объединение существуют в единстве. Концепция МИМ разрабатывается с позиций полисистемного подхода и полидетерминации, которые позволяют выделить в МИМ две системы - 1 и 2. В них входят индивидуальность и ее ближнее окружение, а между ними развертывается психологический квазикаузальный процесс, но в противоположных направлениях в разных системах, если их сравнивать между собой.

Также был раскрыт потенциал полисистемного подхода и полидетерминации для понимания структуры МИМ. Предлагается идея многомерного устройства МИМ. В нем выделяются четыре относительно самостоятельных домена: авторство, обладание, принятие, связанность. При этом система 1 включает домены авторства и обладания, система 2 домены принятия и связанности. Предположительно системы 1 и 2 существуют в параллельном режиме, а психические явления в них трактуются как гомогенные, или однокачественные. Кроме того, эти системы могут пересекаться. На их пересечении возникают иного класса психические явления. Они обозначаются как гетерогенные, или с двойными качествами, поскольку испытывают на себе влияния обеих систем.

Специальное внимание было уделено вопросу пересечения систем 1 и 2. Пересекаясь, они не сливаются, но в каких-то аспектах связаны между собой. Так появляется зона взаимного покрытия, и она может иметь особенности, общие для систем 1 и 2. Также полагаются области пересечения для доменов индивидуальности и области пересечения для доменов ближнего окружения.

Предлагается осуществить переход от понятия общего к понятию целого, а общие области рассматривать маркерами целого. Целое классифицируется по локусу, уровням обобщения и абстракции. Соответственно выделяются МИМ как целое, индивидуальность как целое, ближнее окружение как целое.

В конечном итоге МИМ представлен как многовершинная полисистема, в которой человек в своем МИМ как целом способен переключаться с индивидуальности как целого на ближнее окружение как целое и в обратном направлении. Это может быть связано с самодетерминацией.

Можно наметить некоторые перспективы дальнейших исследований. Желательно определить условные границы МИМ, отличия ближнего окружения от «отдаленного» социального окружения, внятные критерии для введения различий между 
ними. Также следует продолжить поиск психических явлений с двойными качествами. Кроме того, было бы интересно изучить вклады психи- ческих явлений с двойными качествами в образование целого как на уровне МИМ, так и на уровне индивидуальности и ее ближнего окружения.

\section{Литература}

Абульханова, К. А. (2000). С.Л. Рубинштейн - ретроспектива и перспектива. В кн. А. В. Брушлинский, М. И. Воловикова, В. Н. Дружинин (Ред.), Проблема субъекта в психологической науке (с. 13-26). М.: Академический Проект.

Абульханова, К. А. (2012). Развитие психологии в системе комплексного человекознания (ч. 1). М.: Институт психологии РАН.

Айзенк, Г. (1999). Структура личности. М.: КСП+/Ювента.

Айзенк, Г. (2000). Объективность эстетических суждений и их закономерности. В кн. Л. Дорфман, К. Мартиндейл, В. Петров, П. Махотка, Д. Леонтьев, Дж. Купчик (Ред.), Творчество в искусстве - искусство творчества (с. 298-324). М.: Наука/Смысл.

Асмолов, А. Г. (2007). Психология личности: культурно-историческое понимание развития человека (3-е изд., испр. и доп.). М.: Академия/Смысл.

Барабанщиков, В. А. (2007). Системный подход в структуре психологического познания. Методология и история психологии, 2(1), 86-99.

Блауберг, И. В., Садовский, В. Н., Юдин, Э. Г. (1970). Системный подход в современной науке. В кн. И. В. Блауберг, В. Н. Садовский, Э. Г. Юдин (Ред.), Проблемы методологии системного исследования (с. 7-48). М.: Мысль.

Блауберг, И. В., Юдин, Э. Г. (1973). Становление и сущность системного подхода. М.: Наука.

Брушлинский, А. В. (1994). Проблемы психологии субъекта. М.: Институт психологии РАН.

Выготский, Л. С. (1986). Психология искусства (3-е изд.). М.: Искусство.

Вяткин, Б. А. (2007). Лекции по психологии интегральной индивидуальности. Москва/Воронеж: Издательство Московского психолого-социального института/НПО «МОДЭК».

Вяткин, Б. А. (2008). Лекции по психологии интегральной индивидуальности человека. М.: МПСИ. Вяткин, Б. А. (2015). Индивидуальность человека как предмет интегрального исследования. Интегративная перспектива в гуманитарных науках, 1, 36-44.

Вяткин, Б. А., Щукин, М. Р. (2013). Психология стилей человека. Пермь: Книжный мир.

Дергачева, О. Е., Дорфман, Л. Я., Леонтьев, Д. А. (2008). Русскоязычная адаптация опросника каузальных ориентаций. Вестник Московского университета. Сер. 14. Психология, 3, 91-106.

Деркач, А. А., Сайко, Э. В. (2008). Субъектность субъекта в акмеологическом развитии и проблемы его субъектного самоосуществления. Мир психологии, 3, 205-219.

Дорфман, Л. Я. (1993). Метаиндивидуальный мир: методологические и теоретические проблемьь. М.: Смысл.

Дорфман, Л. Я. (1997). Эмоции в искусстве: теоретические подходы и эмпирические исследования. М.: Смысл.

Дорфман, Л. Я. (2004). Я-концепция: дифференциация и интеграция. В кн. Л. Я. Дорфман (Ред.), Интегральная индивидуальность, Я-конщепиия, личность (с. 96-123). М.: Смысл.

Дорфман, Л. Я. (2006). Концепция метаиндивидуального мира: современное состояние. Психология. Журнал Высшей школь экономики, 3(3), 3-34. 
Дорфман, Л. Я. (2007). Метаиндивидуальная и полимодальная модели креативности. В кн. В. М. Петров, А. В. Харуто (Ред.), Информачия, время, творчество (с. 73-79). М.: Государственный институт искусствознания/Московская государственная консерватория им. П.И. Чайковского.

Дорфман, Л. Я. (2008). Методологический анализ теории интегральной индивидуальности В.С. Мерлина. Методология и история психологии, 3(3), 106-121.

Дорфман, Л. Я. (2010). Метаиндивидуальный мир: концепция, приложения, эмпирические свидетельства. Вестник Пермского государственного педагогического университета. Сер. 1. Психология, 1-2, 30-51.

Дорфман, Л. Я. (2012). Эмпирическая парадигма в психологической науке. В кн. А. Л. Журавлев, Т. В. Корнилова, А. В. Юревич (Ред.), Парадигмы в психологии: науковедческий анализ (с. 335-379). М.: Институт психологии РАН.

Дорфман, Л. Я. (2014а). Каузальный плюрализм и психология. Мир психологии, 3(79), 220-236.

Дорфман, Л. Я. (2014б). Каузальный плюрализм и психология (окончание). Мир психологии, $4(80), 230-246$.

Дорфман, Л. Я. (2015). К вопросу диагностики количественных признаков общего в переменных. В кн. Н. А. Батурин (Ред.), Современная психодиагностика России. Преодоление кризиса (т. 1, с. 125-129). Челябинск: Издательский центр ЮУрГУ.

Дорфман, Л. Я. (2016, в печати). Общие и дискриминантные переменные полимодпльного Я. Интегративная перспектива в гуманитарных науках, 2.

Дорфман, Л. Я., Балева, М. В. (2014). Взаимосвязь креативности и вариативности. Психологический журнал, 35(2), 57-67.

Дорфман, Л. Я., Бутакова, А. А. (2015). Вклады веры в интуицию и логического мышления в креативное мышление. В кн. Творчество: наука, искусство, жизнь: Материалы Всероссийской научной конференщии, посвященной 95-летию со дня рождения Я.А. Пономарева, ИП РАН, $24-$ 25 сентября 2015 г. (с. 149-152). М.: Издательство «Институт психологии РАН».

Дорфман, Л. Я., Зубакин, М. В. (2008). Новые данные об эмпирических референтах областей метаиндивидуального мира. В кн. Б. А. Вяткин (Ред.), ХХІІІ Мерлинские чтения: «Активность - индивидуальность - субъект» (с. 35-37). Пермь: Пермский государственный педагогический университет.

Дорфман, Л. Я., Лядов, В. Н. (2015). Метаиндивидуальная модель дисциплинированности (на материале исследования курсантов военного вуза МВД). Вестник Южно-Уральского государственного университета. Серия: Психология, 8(1), 17-28.

Дорфман, Л. Я., Рябикова, М. В., Гольдберг, И. М., Быков, А. Н., Ведров, А. А. (2000). Новая версия Пермского вопросника Я. В кн. Е. А. Малянов, Л. А. Шипицина, Л. Я. Дорфман, С. И. Корниенко, К. Мартиндейл (Ред.), Творчество в образовании, культуре, искусстве (с. 179-183). Пермь: Пермский государственный институт искусства и культуры.

Дорфман, Л. Я., Савинкин, П. И. (2012). Оценки сержантами особенностей личности офицеров и курсантов (на материале военных институтов внутренних войск МВД РФ). Образование и общество, 5(76), 50-54.

Дорфман, Л. Я., Токарева, Г. В. (2013). Эмоциональные предпочтения и полимодальное Я музыканта-исполнителя. Филология и культура/Philology and Culture, 1(31), 235-241.

Дробышева-Разумовская, Л. И., Дорфман, Л. Я., Вяткин, Б. А., Петров, В. М., Зубарева, Н. Б. (2015). Об интегративной перспективе в гуманитарных науках. Интегративная перспектива в гуманитарных науках, 1, 10-20. 
Дубов, И. Г. (1991). Эффекты индивидуально-специфического влияния личности педагога на учащихся. Вопросы психологии, 3, 56-65.

Ильин, Е. П. (2002). Мотивация и мотивы. СПб.: Питер.

Кант, И. (2006). Критика чистого разума. М.: Эксмо.

Корниенко, А. А. (2008). Интегративные тенденции в западной философии науки: к поиску оснований общей теории науки. Вестник Томского государственного университета. Философия. Социология. Политология, 3(4), 34-39.

Корнилова, Т. В. (2006). Экспериментальный метод как путь к причинному объяснению в психологии. Психология. Журнал Высшей школь экономики, 3(2), 3-22.

Корнилова, Т. В., Смирнов, С. Д. (2008). Методологические основы психологии. СПб.:Питер.

Крупенин, А. Л., Крохина, И. М. (1995). Эффективный учитель. Практическая психология для педагогов. Ростов-на-Дону: Феникс.

Кузьмин, В. П. (1982а). Исторические предпосылки и гносеологические основания системного подхода. Психологический журнал, 3(3), 3-14.

Кузьмин, В. П. (1982б). Исторические предпосылки и гносеологические основания системного подхода: (Окончание). Психологический журнал, 3(4), 3-13.

Леонтьев, А. Н. (1971). Потребности, мотивы и эмоции. М.: Изд-во Московского университета.

Леонтьев, А. Н. (2001). Лекиии по общей психологии. М.: Смысл.

Леонтьев, Д. А. (1992). Жизненный мир человека и проблема потребностей. Психологический журнал, 13(2), 107-120.

Леонтьев, Д. А. (2000). Психология свободы: к постановке проблемы самодетерминации личности. Психологический журнал, 21(1), 15-25.

Леонтьев, Д. А. (2001). Жизнетворчество как практика расширения жизненного мира. В кн. Д. А. Леонтьев, Е. С. Мазур, А. И. Сосланд (Ред.), 1-я Всероссийская научно-практическая конференция по экзистенциальной психологии (с. 100-109). М.: Смысл.

Леонтьев, Д. А. (2006). Личностный потенциал как потенциал саморегуляции. В кн. Б. С. Братусь, Е. Е. Соколова (Ред.), Уиеные записки кафедры общей психологии МГУ (вып. 2, с. 85-105). М.: Смысл.

Леонтьев, Д. А. (2011). Новые ориентиры понимания личности в психологии: от необходимого к возможному. Вопросы психологии, 1, 3-27.

Ломов, Б. Ф. (1984). Методологические и теоретические проблемы психологии. М.: Наука.

Мерлин, В. С. (1971). Лекиии по психологии мотивов человека. Пермь: Пермское книжное изд-во.

Мерлин, В. С. (1978). Деятельность как опосредующее звено в связи разноуровневых свойств индивидуальности. В кн. В. С. Мерлин (Ред.), Проблемь интегрального исследования индивидуальности (вып. 2, с. 15-40). Пермь: Пермский государственный педагогический институт.

Мерлин, В. С. (1986). Очерк интегрального исследования индивидуальности. М.: Педагогика.

Моросанова, В. И. (2007). Индивидуальная саморегуляция и характер человека. Вопросы психологии, 3, 59-68.

Небылицын, В. Д. (1990). Избранные психологические труды. М.: Педагогика.

Осницкий, А. К. (2007). Регуляция деятельности и направленность личности. М.: Изд-во Московского экономико-лингвистического института.

Петров, В. М., Мажуль, Л. А. (2014). Исследования креативности: экспансия интегративной тенденции (по материалам осенних научно-практических конференций). Мир психологии, 1(77), 267-273.

Петровский, А. В., Петровский, В. А. (1982). Индивид и его потребность быть личностью. Вопросы философии, 3, 44-54. 
Петровский, В. А. (1981а). К пониманию личности в психологии. Вопросы психологии, 2, 40-46. Петровский, В. А. (1981б). Проблемы психологии личности в свете идей Л.С. Выготского. В кн. Научное творчество Л.С. Выготского и современная психология: Тезисы докладов Всесоюзной конференции (с. 122-125). М.

Петровский, В. А. (1985). Принцип отраженной субъектности в психологическом исследовании личности. Вопросы психологии, 4, 17-40.

Петровский, В. А. (1997). Очерк теории свободной причинности. В кн. Д. А. Леонтьев, В. Г. Щур (Ред.), Психология с человеческим лицом: гуманистическая перспектива в постсоветской психологии (с. 124-144). М.: Смысл.

Петровский, В. А. (2009). Логика «Я»: персонологическая перспектива. Самара: Изд-во САМГУ.

Петровский, В. А. (2013). «Я» в персонологической перспективе. М.: Издательский дом НИУ ВШЭ.

Петровский, В. А., Гуренкова, И. П. (1985). Новая модификация фрустрационного метода. В кн. Личность в общении и деятельности: Межвузовский сборник научных трудов (с. 37-43). Ульяновск: Ульяновский государственный педагогический университет им. И.Н. Ульянова.

Петровский, В. А., Кузьмина, Е. И. (1988). Надситуативная активность и ее исследование в детском возрасте. В кн. Личность и межличностные отношения в коллективе (с. 105-110). Ульяновск: Ульяновский государственный педагогический университет им. И.Н. Ульянова.

Петровский, В. А., Старовойтенко, Е. Б. (2012). Наука личности: четыре проекта общей персонологии. Психология. Журнал Высшей школь экономики, 9(1), 21-39.

Рубинштейн, С. Л. (2003). Бытие и сознание. Человек и мир. СПб.: Питер.

Толочек, В. А. (2013). Проблема стилей в психологии: историко-теоретический анализ. М.: Институт психологии РАН.

Ушаков, Д. В. (2006). Языки психологии творчества: Яков Александрович Пономарев и его научная школа. В кн. Д. В. Ушаков (Ред.), Психология творчества: школа Я.А. Пономарева (с. 19-142). М.: Институт психологии РАН.

Хекхаузен, Х. (2001). Психология мотивачии достижения. М.: Речь.

Шадриков, В. Д. (2013). Психология деятельности человека. М.: Институт психологии РАН.

Штерн, В. (1998). Дифференциальная психология и ее методические основы. М.: Наука.

Юревич, А. В. (2007). Парадигмы в психологии. Методология и история психологии, 2, 3-17.

Юревич, А. В. (2012). Естественнонаучная и гуманитарная парадигмы в психологии. В кн. А. Л. Журавлев, Т. В. Корнилова, А. В. Юревич (Ред.), Парадигмы в психологии: науковедческий анализ (c. 13-33). М.: Институт психологии РАН.

Alessi, G. (1992). Models of proximate and ultimate causation in psychology. American Psychologist, 47(11), 1359-1370. doi:10.1037/0003-066X.47.11.1359

Almstrom, C. (2006). A three-worldview of System Justification Theory. Journal of Scientific Psychology, 9, 6-8.

Avital, T. (2003). Art versus nonart: Art out of mind. Cambridge, UK: Cambridge University Press.

Baker, T. B., Piper, M. E., McCarthy, D. E., Majeskie, M. R., \& Fiore, M. C. (2004). Addiction motivation reformulated: An affective processing model of negative reinforcement. Psychological Review, 111(1), 33-51. doi:10.1037/0033-295X.111.1.33

Bandura, A. (2002). Social cognitive theory in cultural context. Applied Psychology, 51(2), 269-290. doi:10.1111/1464-0597.00092

Barry, C. M., \& Wentzel, K. R. (2006). Friend influence on prosocial behavior: The role of motivational factors and friendship characteristics. Developmental Psychology, 42(1), 153-163. doi:10.1037/ 0012-1649.42.1.153 
Berlyne, D. E. (Ed.). (1974). Studies in the new experimental aesthetics. Washington, DC: Hemi-sphere. doi:10.2307/3344649

Blatt, S. J. (2008). Polarities of experience: Relatedness and self-definition in personality development, psychopathology, and the therapeutic process. Washington, DC: American Psychological Association.

Brewer, M. B. (2013). 25 years toward a multilevel science. Perspectives on Psychological Science, 8(5), 554-555. doi:10.1177/1745691613500996

Burgoon, E. M., Henderson, M. D., \& Markman, A. B. (2013). There are many ways to see the forest for the trees: A tour guide for abstraction. Perspectives on Psychological Science, 8(5), 501-520. doi:10.1177/1745691613497964

Cameron, J., Pierce, W. D., Banko, K. M., \& Gear, A. (2005). Achievement-based rewards and intrinsic motivation: A test of cognitive mediators. Journal of Educational Psychology, 97(4), 641-655. doi:10.1037/0022-0663.97.4.641

Deci, E. L., Koestner, R., \& Ryan, R. M. (1999). The undermining effect is a reality after all-extrinsic rewards, task interest, and self-determination. Reply to Eisenberg, Pierce, and Cameron and Lepper, Henderlong, and Gingras. Psychological Bulletin, 125(6), 692-700. doi:10.1037/0033-2909.125.6.692

Deci, E. L., \& Ryan, R. M. (2012). Self-determination theory. In P. A. M. V. Lange, A. W. Kruglanski, \& E. T. Higgins (Eds.), Handbook of theories of social psychology (Vol. 1, pp. 416-437). Thousand Oaks, CA: Sage. doi:10.4135/9781446201022

Dorfman, L. (1995). Meta-individual world. Studia Psychologica, 37(4), 279-286.

Dorfman, L., \& Ogorodnikova, A. (2007). Plural self, plural achievement motives, and creative thinking. In L. Dorfman, C. Martindale, \& V. Petrov (Eds.), Aesthetics and innovation (pp. 125-160). Cambridge, UK: Cambridge Scholars Press.

Echterhoff, G. E., Higgins, T., \& Levine, J. M. (2009). Shared reality: Experiencing commonality with others' inner states about the world. Perspectives on Psychological Science, 4(5), 496-521. doi:10.1111/j.1745-6924.2009.01161.x

Eysenck, H. J. (1967). The biological basis of personality. Springfield, IL: Thomas.

Fox, E., Russo, R., Bowles, R., \& Dutton, K. (2002). Do threatening stimuli draw or hold visual attention in subclinical anxiety? Journal of Experimental Psychology: General, 130(4), 681-700. doi:10.1037/0096-3445.130.4.681

Friedman, R. S., \& Förster, J. (2005). Effects of motivational cues on perceptual asymmetry: Implications for creativity and analytical problem solving. Journal of Personality and Social Psychology, 88(2), 263-275. doi:10.1037/0022-3514.88.2.263

Hall, N. (2000). Causation and the price of transitivity. Journal of Philosophy, 97, 198-222. doi: $10.2307 / 2678390$.

Harré, R. (1979). Social being: A theory for social psychology. Oxford: Blackwell.

Hausman, D. M. (1998). Causal asymmetries. New York: Cambridge University Press.

Heidegger, M. (2005). Introduction to phenomenological research. Bloomington, IN: Indiana University Press.

Hofmann, W., Friese, M., \& Strack, F. (2009). Impulse and self-control from a dual-systems perspective. Perspectives on Psychological Science, 4(2), 162-176. doi:10.1111/j.1745-6924.2009.01116.x

James, K., \& Eisenberg, J. (2004). Personal identity and group identity influences on algorithmic and original task performance. Creativity Research Journal, 16(1), 91-103. doi:10.1207/ s15326934crj1601_9

James, W. (1904/1976). Does consciousness exist? Essays in radical empiricism. Cambridge, MA: Harvard University Press. 
Magnusson, D. (2001). The holistic-interactionistic paradigm: Some directions for empirical developmental research. European Psychologist, 6, 153-162. doi:10.1027//1016-9040.6.3.153

Martindale, C. (1980). Subselves. The internal representation of situational and personal dispositions. In L. Wheeler (Ed.), Review of personality and social psychology (Vol. 1, pp. 193-218). Beverly Hills, CA: Sage.

McGuire, W. J. (2004). A perspectivist approach to theory construction. Personality and Social Psychology Review, 8(2), 173-182. doi:10.1207/s15327957pspr0802_11

Mead, G. H. (1934). Mind, self, and society. Chicago: University of Chicago Press.

Mischel, W. (2009). Becoming a cumulative science. Observer, 22, 1.

Mischel, W., \& Shoda, Y. (1998). Reconciling processing dynamics and personality dispositions. Annual Review of Psychology, 49, 229-258. doi:10.1146/annurev.psych.49.1.229

Pacini, R., \& Epstein, S. (1999). The relation of rational and experiential information processing styles to personality, basic beliefs, and the ratio-bias phenomenon. Journal of Personality and Social Psychology, 76(6), 972-987. doi:10.1037/0022-3514.76.6.972

Pervin, L. A. (2001). A dynamic systems approach to personality. European Psychologist, 6(3), 172-176. doi:10.1027//1016-9040.6.3.172

Pierce, J. L., Kostova, T., \& Dirks, K. T. (2003). The state of psychological ownership: Integrating and extending a century of research. Review of General Psychology, 7(1), 84-107. doi:10.1037/1089-2680.7.1.84

Reiss, S. (2004). Multifaceted nature of intrinsic motivation: The theory of 16 basic desires. Review of General Psychology, 8(3), 179-193. doi:10.1027//1016-9040.6.3.172

Salmon, W. (1998). Causality and explanation. New York: Oxford University Press.

Sowden, P. T., Pringle, A., \& Gabora, L. (2015). The shifting sands of creative thinking: Connections to dual process theory. Thinking and Reasoning, 21(1), 40-60. doi:10.1080/13546783.2014.885464

Sternberg, R. J. (2003). Unify! Monitor on Psychology, 35(2), 5. doi:10.1037/e300052003-002

Tay, L., \& Diener, E. (2011). Needs and subjective well-being around the world. Journal of Personality and Social Psychology, 101(2), 354-365. doi:10.1037/a0023779

Van der Weiden, A., Ruys, K. I., \& Aarts, H. (2013). A matter of matching: How goals and primes affect self-agency experiences. Journal of Experimental Psychology: General, 142(3), 954-966. doi:10.1037/a0030079

Witherington, D. C., \& Crichton, J. A. (2007). Frameworks for understanding emotions and their development: Functionalist and dynamic systems approaches. Emotion, 7(3), 628-637. doi:10.1037/1528-3542.7.3.628

Zuckerman, M. (2007). Sensation seeking. In M. Zuckerman, Sensation seeking and risky behavior (pp. 3-49). Washington, DC: American Psychological Association.

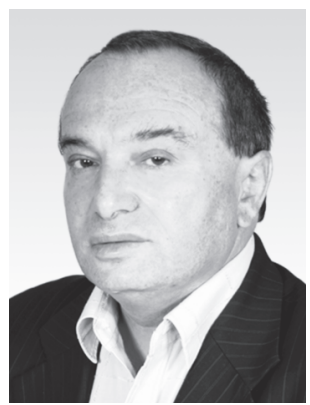

Дорфман Леонид Яковлевич - заведующий кафедрой психологии и педагогики Пермского государственного института культуры, доктор психологических наук, профессор.

Контакты: dorfman07@yandex.ru 


\title{
The Causal Pluralism and Holism in the Meta-Individual World Theory
}

\author{
Leonid Ya. Dorfman
}

${ }^{a}$ Perm State Institute of Culture, 18 Gazeta Zvezda Str., Perm, 614000, Russian Federation

\begin{abstract}
The current study was intended to present a current version of the meta-individual world (MIW) theory developed by Dorfman. Its core is the dual-system model. According to it, two systems are specified, namely, System 1 and System 2. One of the systems (System 1) unifies the personality and its closer social setting. Within this system, the personality extends to its closer social setting, making changes in it. Thus, the personality occupies the primary position and the closer social setting occupies the secondary position. This system carries a connection of the closer social setting to the personality. The other system (System 2) also connects the closer social setting to the personality, but in the opposite direction. Within this system, the closer social setting extends to the personality, making changes in it. Here, the closer social setting occupies the primary position and the personality occupies the secondary position. The two systems are distinct, operate in their own right and are relatively independent from one another, although they hold a common personal and social ground. Respectively, two kinds of phenomena are specified, namely, within each system and those under influence of the both systems. Thus, the latter brings dual qualities. In addition, a structuralist view is employed; it is shown on the lines of multidimensionality, namely, agency, possession, perspective-taking, and relatedness.
\end{abstract}

Keywords: meta-individual world, causal pluralism, holism, dual-system model, phenomena with one quality, phenomena with dual qualities.

\section{References}

Abulkhanova, K. A. (2000). S.L. Rubinshtein - retrospektiva i perspektiva [S.L. Rubinstein - retrospective and perspective]. In A. V. Brushlinskii, M. I. Volovikova, V. N. Druzhinin (Eds.), Problema sub"ekta v psikhologicheskoi nauke [The problem of subject in psychological science] (pp. 13-26). Moscow: Akademicheskii Proekt.

Abulkhanova, K. A. (2012). Razvitie psikhologii v sisteme kompleksnogo chelovekoznaniya [Development of psychology in the system of complex human studies] (Pt. 1). Moscow: Institute of Psychology of Russian Academy of Sciences.

Alessi, G. (1992). Models of proximate and ultimate causation in psychology. American Psychologist, 47(11), 1359-1370. doi:10.1037/0003-066X.47.11.1359

Almstrom, C. (2006). A three-worldview of System Justification Theory. Journal of Scientific Psychology, 9, 6-8.

Asmolov, A. G. (2007). Psikhologiya lichnosti: kul'turno-istoricheskoe ponimanie razvitiya cheloveka [Personality psychology: Cultural-historical understanding of development of man]. Moscow: Akademiya/Smysl. 
Avital, T. (2003). Art versus nonart: Art out of mind. Cambridge, UK: Cambridge University Press.

Baker, T. B., Piper, M. E., McCarthy, D. E., Majeskie, M. R., \& Fiore, M. C. (2004). Addiction motivation reformulated: An affective processing model of negative reinforcement. Psychological Review, 111(1), 33-51. doi:10.1037/0033-295X.111.1.33

Bandura, A. (2002). Social cognitive theory in cultural context. Applied Psychology, 51(2), 269-290. doi:10.1111/1464-0597.00092

Barabanshchikov, V. A. (2007). Sistemnyi podkhod v strukture psikhologicheskogo poznaniya [Systemic approach in the structure of psychological cognition]. Metodology and History of Psychology, 2(1), 86-99.

Barry, C. M., \& Wentzel, K. R. (2006). Friend influence on prosocial behavior: The role of motivational factors and friendship characteristics. Developmental Psychology, 42(1), 153-163. doi:10.1037/ 0012-1649.42.1.153

Berlyne, D. E. (Ed.). (1974). Studies in the new experimental aesthetics. Washington, DC: Hemi-sphere. doi: $10.2307 / 3344649$

Blatt, S. J. (2008). Polarities of experience: Relatedness and self-definition in personality development, psychopathology, and the therapeutic process. Washington, DC: American Psychological Association.

Blauberg, I. V., \& Yudin, E. G. (1973). Stanovlenie i sushchnost' sistemnogo podkhoda [The formation and the essence of systemic approach]. Moscow: Nauka.

Blauberg, I. V., Sadovskii, V. N., \& Yudin, E. G. (1970). Sistemnyi podkhod v sovremennoi nauke [Systemic approach in modern science]. In I. V. Blauberg, V. N. Sadovskii, \& E. G. Yudin (Eds.), Problemy metodologii sistemnogo issledovaniya [Issues of methodology of systemic research] (pp. 7-48). Moscow: Mysl'.

Brewer, M. B. (2013). 25 years toward a multilevel science. Perspectives on Psychological Science, 8(5), 554-555. doi:10.1177/1745691613500996

Brushlinskii, A. V. (1994). Problemy psikhologii sub"ekta [Issues of psychology of subject]. Moscow: Institute of Psychology of Russian Academy of Sciences.

Burgoon, E. M., Henderson, M. D., \& Markman, A. B. (2013). There are many ways to see the forest for the trees: A tour guide for abstraction. Perspectives on Psychological Science, 8(5), 501-520. doi:10.1177/1745691613497964

Cameron, J., Pierce, W. D., Banko, K. M., \& Gear, A. (2005). Achievement-based rewards and intrinsic motivation: A test of cognitive mediators. Journal of Educational Psychology, 97(4), 641-655. doi:10.1037/0022-0663.97.4.641

Deci, E. L., \& Ryan, R. M. (2012). Self-determination theory. In P. A. M. V. Lange, A. W. Kruglanski, \& E. T. Higgins (Eds.), Handbook of theories of social psychology (Vol. 1, pp. 416-437). Thousand Oaks, CA: Sage. doi:10.4135/9781446201022

Deci, E. L., Koestner, R., \& Ryan, R. M. (1999). The undermining effect is a reality after all-extrinsic rewards, task interest, and self-determination. Reply to Eisenberg, Pierce, and Cameron and Lepper, Henderlong, and Gingras. Psychological Bulletin, 125(6), 692-700. doi:10.1037/00332909.125.6.692

Dergacheva, O. E., Dorfman, L. Ya., \& Leontiev, D. A. (2008). Russian adaptation of the General Causality Orientation Scale. Vestnik Moskovskogo Universiteta. Seriya 14. Psikhologiya, 3, 91-106.

Derkach, A. A., \& Saiko, E. V. (2008). Sub"ektnost' sub"ekta v akmeologicheskom razvitii i problemy ego sub"ektnogo samoosushchestrleniya [Subjectivity of subject in acmeological development an problems of its subjective self-actualization]. Mir Psikhologii, 3, 205-219. 
Dorfman, L. (1995). Meta-individual world. Studia Psychologica, 37(4), 279-286.

Dorfman, L. Y., \& Tokareva, G. V. (2013). Emotional preferences and the polymodal self-concept of a performing musician. Filologiya i kul'tura/Philology and Culture, 1(31), 235-241.

Dorfman, L. Ya. (1993). Metaindividual'nyi mir: metodologicheskie i teoreticheskie problemy [Meta-individual world: Methodological and theoretical issues]. Moscow: Smysl.

Dorfman, L. Ya. (1997). Emotsii v iskusstve: teoreticheskie podkhody i empiricheskie issledovaniya [Emotions in art: Theoretical approaches and empirical studies]. Moscow: Smysl.

Dorfman, L. Ya. (2004). Ya-kontseptsiya: differentsiatsiya i integratsiya [Self-concept: Differentiation and integration]. In L. Ya. Dorfman (Ed.), Integral'naya individual'nost', Ya-kontseptsiya, lichnost' [Integral individuality: Self-concept, personality] (pp. 96-123). Moscow: Smysl.

Dorfman, L. Ya. (2006). Conception of the metaindividual world: the state of the art. Psychology. Journal of the Higher School of Economics, 3(3), 3-34.

Dorfman, L. Ya. (2007). Metaindividual'naya i polimodal'naya modeli kreativnosti [Metaindividual and polymodal models of creativity]. In V. M. Petrov \& A. V. Kharuto (Eds.), Informatsiya, vremya, tvorchestvo [Information, time, creativity] (pp. 73-79). Moscow: State Institute for Art Studies/Moscow P.I. Tchaikovsky Conservatory.

Dorfman, L. Ya. (2008). Metodologicheskii analiz teorii integral'noi individual'nosti V.S. Merlina [Methodological analysis of theories of integral individuality by V.S. Merlin]. Methodology and History of Psychology, 3(3), 106-121.

Dorfman, L. Ya. (2010). Metaindividual'nyi mir: kontseptsiya, prilozheniya, empiricheskie svidetel'stva [Meta-individual world: conception, applications, empirical evidence]. Vestnik Permskogo Gosudarstvennogo Pedagogicheskogo Universiteta. Seriya 1. Psikhologiya, 1-2, 30-51.

Dorfman, L. Ya. (2012). Empiricheskaya paradigma v psikhologicheskoi nauke [Empirical paradigm in psychological science]. In A. L. Zhuravlev, T. V. Kornilova, \& A. V. Yurevich (Eds.), Paradigmy v psikhologii: naukovedcheskii analiz [Paradigms in psychology: scientific analysis] (pp. 335-379). Moscow: Institute of Psychology of Russian Academy of Sciences.

Dorfman, L. Ya. (2014a). Kauzal'nyi plyuralizm i psikhologiya [Causal pluralism and psychology]. Mir Psikhologii, 3(79), 220-236.

Dorfman, L. Ya. (2014b). Kauzal'nyi plyuralizm i psikhologiya (okonchanie) [Causal pluralism and psychology (conclusion)]. Mir Psikhologii, 4(80), 230-246.

Dorfman, L. Ya. (2015). K voprosu diagnostiki kolichestvennykh priznakov obshchego v peremennykh [On the diagnostics of quantitative attributes of the common in variables]. In N. A. Baturin (Ed.), Sovremennaya psikhodiagnostika Rossii. Preodolenie krizisa [Modern psychodiagnostics in Russia: Overcoming crisis] (Vol. 1, pp. 125-129). Chelyabinsk: South Ural State University.

Dorfman, L. Ya., \& Liadov, V. N. (2015). The meta-individual model of discipline (based on Cadets at the Military University of the Russian Internal Troops). Bulletin of the South Ural State University. Seriya Psychology, 8(1), 17-28.

Dorfman, L. Ya., \& Savinkin, P. I. (2012). Otsenki serzhantami osobennostei lichnosti ofitserov i kursantov (na materiale voennykh institutov vnutrennikh voisk MVD RF) [Evaluations by sergeants of personality characteristics of officers and cadets (on the material of military institutes of internal military troops of Ministry of Internal Affairs of the Russian Federation]. Education and Society, 5(76), 50-54. 
Dorfman, L. Ya., \& Zubakin, M. V. (2008). Novye dannye ob empiricheskikh referentakh oblastei metaindividual'nogo mira [New data on empirical referents of domains of metaindividual world]. In B. A. Vyatkin (Ed.), XXIII Merlinskie chteniya: "Aktivnost' - individual'nost'- sub"ekt" [XXIII Merlin Readings: "Activity - Individuality - Subject"] (pp. 35-37). Perm: Perm State Pedagogical University.

Dorfman, L. Ya., Ryabikova, M. V., Gol'dberg, I. M., Bykov, A. N., \& Vedrov, A. A. (2000). Novaya versiya Permskogo voprosnika Ya [New version of perm questionnaire of self]. In E. A. Malyanov, L. A. Shipitsina, L. Ya. Dorfman, S. I. Kornienko, \& C. Martindeil (Eds.), Tvorchestvo v obrazovanii, kul'ture, iskusstve [Creativity in education, culture, art] (pp. 179-183). Perm: Perm State Institute of Culture.

Dorfman, L., \& Baleva, M. V. (2014). Correlation between creativity and variativity. Psikhologicheskii Zhurnal, 35(2), 57-67.

Dorfman, L., \& Ogorodnikova, A. (2007). Plural self, plural achievement motives, and creative thinking. In L. Dorfman, C. Martindale, \& V. Petrov (Eds.), Aesthetics and innovation (pp. 125-160). Cambridge, UK: Cambridge Scholars Press.

Drobysheva-Razumovskaya, L. I., Dorfman, L. Ya., Vyatkin, B. A., Petrov, V. M., \& Zubareva, N. B. (2015). On to integrative perspective in humanities. Integrative Perspective in Humanities, 1, 10-20.

Dubov, I. G. (1991). Effekty individual'no-spetsificheskogo vliyaniya lichnosti pedagoga na uchashchikhsya [Effects of individual-specific influence of teacher's personality on students]. Voprosy Psikhologii, 3, 56-65.

Echterhoff, G. E., Higgins, T., \& Levine, J. M. (2009). Shared reality: Experiencing commonality with others' inner states about the world. Perspectives on Psychological Science, 4(5), 496-521. doi:10.1111/j.1745-6924.2009.01161.x

Eysenck, H. J. (1967). The biological basis of personality. Springfield, IL: Thomas.

Eysenck, H. J. (1999). Struktura lichnosti [The structure of personality]. Moscow: KSP+/Yuventa. (Transl. of: Eysenck, H. J. (1953). The structure of human personality. London: Mehtuen).

Eysenck, H. J. (2000). Ob"ektivnost' esteticheskikh suzhdenii i ikh zakonomernosti [Objectivity of aesthetic judgments and their regularities]. In L. Dorfman, C. Martindeil, V. Petrov, P. Machotka, D. Leontiev, \& G. Cupchik (Eds.), Toorchestvo v iskusstve - iskusstvo tvorchestva [Creativity in art - the art of creativity] (pp. 298-324). Moscow: Nauka/Smysl.

Fox, E., Russo, R., Bowles, R., \& Dutton, K. (2002). Do threatening stimuli draw or hold visual attention in subclinical anxiety? Journal of Experimental Psychology: General, 130(4), 681-700. doi:10.1037/0096-3445.130.4.681

Friedman, R. S., \& Förster, J. (2005). Effects of motivational cues on perceptual asymmetry: Implications for creativity and analytical problem solving. Journal of Personality and Social Psychology, 88(2), 263-275. doi:10.1037/0022-3514.88.2.263

Hall, N. (2000). Causation and the price of transitivity. Journal of Philosophy, 97, 198-222. doi: $10.2307 / 2678390$.

Harré, R. (1979). Social being: A theory for social psychology. Oxford: Blackwell.

Hausman, D. M. (1998). Causal asymmetries. New York: Cambridge University Press.

Heckhausen, H. (2001). Psikhologiya motivatsii dostizheniya [The psychology of achievement motivation]. Moscow: Rech'. (Transl. of: Heckhausen, H. (1980). Motivation und Handeln. Lehrbuch der Motivationspsychologie. Berlin: Springer. (in German)).

Heidegger, M. (2005). Introduction to phenomenological research. Bloomington, IN: Indiana University Press. 
Hofmann, W., Friese, M., \& Strack, F. (2009). Impulse and self-control from a dual-systems perspective. Perspectives on Psychological Science, 4(2), 162 176. doi:10.1111/j.1745-6924.2009.01116.x

Il'in, E. P. (2002). Motivatsiya i motivy [Motivation and motives]. Saint Petersburg: Piter.

James, K., \& Eisenberg, J. (2004). Personal identity and group identity influences on algorithmic and original task performance. Creativity Research Journal, 16(1), 91-103. doi:10.1207/ s15326934crj1601_9

James, W. (1904/1976). Does consciousness exist? Essays in radical empiricism (pp. 3-19). Cambridge, MA: Harvard University Press.

Kant, I. (2006). Kritika chistogo razuma [Critique of pure reason] Moscow: Eksmo. (Transl. of: Kant, I. (1787). Kritik der reinen Vernunft. Zweite, hin und wieder verbesserte Auflage. Riga: Hartknoch. (in German)).

Kornienko, A. A. (2008). Integrativnye tendentsii v zapadnoi filosofii nauki: k poisku osnovanii obshchei teorii nauki [Integrative tendencies in the Western philosophy of science: On search of grounds for the general theory of science]. Tomsk State University Journal of Philosophy, Sociology and Political Science, 3(4), 34-39.

Kornilova, T. V. (2006). Experimental method as a way towards causal explanation in psychology. Psychology. Journal of the Higher School of Economics, 3(2), 3-22.

Kornilova, T. V., \& Smirnov, S. D. (2008). Metodologicheskie osnovy psikhologii [Methodological foundations of psychology]. Saint Petersburg: Piter.

Krupenin, A. L., \& Krokhina, I. M. (1995). Effektivnyi uchitel'. Prakticheskaya psikhologiya dlya pedagogov [Efficient teacher. Practical psychology for educators]. Rostov-on-Don: Feniks.

Kuz'min, V. P. (1982a). Istoricheskie predposylki i gnoseologicheskie osnovaniya sistemnogo podkhoda [Historical prerequisites an gnoseological grounds of systemic approach]. Psikhologicheskii Zhurnal, 3(3), 3-14.

Kuz'min, V. P. (1982b). Istoricheskie predposylki i gnoseologicheskie osnovaniya sistemnogo podkhoda: (Okonchanie) [Historical prerequisites and gnoseological grounds of systemic approach (conclusion]. Psikhologicheskii Zhurnal, 3(4), 3-13.

Leontiev, A. N. (1971). Potrebnosti, motivy i emotsii [Needs, motives and emotions]. Moscow: Moscow University Press.

Leontiev, A. N. (2001). Lektsii po obshchei psikhologii [Lectures on general psychology]. Moscow: Smysl.

Leontiev, D. A. (1992). Zhiznennyi mir cheloveka i problema potrebnostei [Life-world of man and the problem of needs]. Psikhologicheskii Zhurnal, 13(2), 107-120.

Leontiev, D. A. (2000). The psychology of freedom: Toward the investigation of person's self-determination. Psikhologicheskii Zhurnal, 21(1), 15-25.

Leontiev, D. A. (2001). Zhiznetvorchestvo kak praktika rasshireniya zhiznennogo mira [Life-creativity as a practice of widening of the life-world]. In D. A. Leontiev, E. S. Mazur, \& A. I. Sosland (Eds.), 1-ya Vserossiiskaya nauchno-prakticheskaya konferentsiya po ekzistentsial'noi psikhologii [First AllRussian Applied Research Conference on Existential Psychology] (pp. 100-109). Moscow: Smysl.

Leontiev, D. A. (2006). Lichnostnyi potentsial kak potentsial samoregulyatsii [Personality potential as potential of self-regulation]. In B. S. Bratus \& E. E. Sokolova (Eds.), Uchenye zapiski kafedry obshchei psikhologii MGU [Scholarly notes of the Chair of General Psychology of Moscow State University] (Iss. 2, pp. 85-105). Moscow: Smysl.

Lomov, B. F. (1984). Metodologicheskie i teoreticheskie problemy psikhologii [Methodological and theoretical issues of psychology]. Moscow: Nauka. 
Magnusson, D. (2001). The holistic-interactionistic paradigm: Some directions for empirical developmental research. European Psychologist, 6, 153-162. doi:10.1027//1016-9040.6.3.153

Martindale, C. (1980). Subselves. The internal representation of situational and personal dispositions. In L. Wheeler (Ed.), Review of personality and social psychology (Vol. 1, pp. 193-218). Beverly Hills, CA: Sage.

McGuire, W. J. (2004). A perspectivist approach to theory construction. Personality and Social Psychology Review, 8(2), 173-182. doi:10.1207/s15327957pspr0802_11

Mead, G. H. (1934). Mind, self, and society. Chicago: University of Chicago Press.

Merlin, V. S. (1971). Lektsii po psikhologii motivov cheloveka [Lectures on psychology of human motives]. Perm: Permskoe Knizhnoe Izdatel'stvo.

Merlin, V. S. (1978). Deyatel'nost' kak oposreduyushchee zveno v svyazi raznourovnevykh svoistv individual'nosti [Activity as a mediating link in relations of various-level qualities of individuality]. In V. S. Merlin (Ed.), Problemy integral'nogo issledovaniya individual'nosti [Issues of integral research of individuality] (Iss. 2, pp. 15-40). Perm: Perm State Pedagogical Insitute.

Merlin, V. S. (1986). Ocherk integral'nogo issledovaniya individual'nosti [Essay on integral research of individuality]. Moscow: Pedagogika.

Mischel, W. (2009). Becoming a cumulative science. Observer, 22, 1.

Mischel, W., \& Shoda, Y. (1998). Reconciling processing dynamics and personality dispositions. Annual Review of Psychology, 49, 229-258. doi:10.1146/annurev.psych.49.1.229

Morosanova, V. I. (2007). Individual self-regulation and human character. Voprosy Psikhologii, 3, 5968.

Nebylitsyn, V. D. (1990). Izbrannye psikhologicheskie trudy [Selected psychological works]. Moscow: Pedagogika.

Osnitsky, A. K. (2007). Regulyatsiya deyatel'nosti i napravlennost' lichnosti [Regulation of activity and directivity of personality]. M.: Izdatel'stvo Moskovskogo Ekonomiko-Lingvisticheskogo Instituta.

Pacini, R., \& Epstein, S. (1999). The relation of rational and experiential information processing styles to personality, basic beliefs, and the ratio-bias phenomenon. Journal of Personality and Social Psychology, 76(6), 972-987. doi:10.1037/0022-3514.76.6.972

Pervin, L. A. (2001). A dynamic systems approach to personality. European Psychologist, 6(3), 172 176. doi:10.1027//1016-9040.6.3.172

Petrov, V. M., \& Mazhul, L. A. (2014). Issledovaniya kreativnosti: ekspansiya integrativnoi tendentsii (po materialam osennikh nauchno-prakticheskikh konferentsii) [Studies on creativity: expansion of integrative tendency (on the materials of autumn applied science conferences]. Mir Psikhologii, 1(77), 267-273.

Petrovskiy, A. V., \& Petrovskiy, V. A. (1982). Individ i ego potrebnost' byt' lichnost'yu [Individual and his need to be personality]. Voprosy Filosofii, 3, 44-54.

Petrovskiy, V. A. (1981a). K ponimaniyu lichnosti v psikhologii [On the understanding of personality in psychology]. Voprosy Psikhologii, 2, 40-46.

Petrovskiy, V. A. (1981b). Problemy psikhologii lichnosti v svete idei L.S. Vygotskogo [Issues of the personality psychology in light of ideas of L.S. Vygotsky]. In Nauchnoe tvorchestvo L.S. Vygotskogo i sovremennaya psikhologiya: Tezisy dokladov Vsesoyuznoi konferentsii [Scientific works by L.S. Vygotsky and modern psychology: Theses from All-Union Conference] (pp. 122-125). Moscow.

Petrovskiy, V. A. (1985). Printsip otrazhennoi sub»ektnosti v psikhologicheskom issledovanii lichnosti [The principle of reflected subjectivity in psychological research on personality]. Voprosy Psikhologii, 4, 17-40. 
Petrovskiy, V. A. (1997). Ocherk teorii svobodnoi prichinnosti [Essay on the theory of free causality]. In D. A. Leontiev \& V. G. Shchur (Eds.), Psikhologiya s chelovecheskim litsom: gumanisticheskaya perspektiva v postsovetskoi psikhologii [Psychology with a human face: Humanistic perspective in postsoviet psychology] (pp. 124-144). Moscow: Smysl.

Petrovskiy, V. A. (2009). Logika "Ya": personologicheskaya perspektiva [Logic of Self: A personological perspective]. Samara: Publishing House "Samara University".

Petrovskiy, V. A. (2013). "Ya" v personologicheskoi perspektive [Self in personological perspective]. M.: The Publishing House of the Higher School of Economics.

Petrovskiy, V. A., \& Gurenkova, I. P. (1985). Novaya modifikatsiya frustratsionnogo metoda [New modification of frustration method]. In Lichnost' v obshchenii i deyatel'nosti: Mezhvuzovskii sbornik nauchnykh trudov [Personality in communication and activity: Interuniversity collection of scientific works] (pp. 37-43). Ulyanovsk: Ulyanovsk State Pedagogical Institute.

Petrovskiy, V. A., \& Kuz'mina, E. I. (1988). Nadsituativnaya aktivnost' i ee issledovanie v detskom vozraste [Oversituational activity and its study in children]. In Lichnost' $i$ mezhlichnostnye otnosheniya v kollektive [Personality and interpersonal relationships in a group] (pp. 105-110). Ulyanovsk: Ulyanovsk State Pedagogical Institute.

Petrovskiy, V. A., \& Starovoytenko, E. B. (2012). The science of personality: Four projects of general personology. Psychology. Journal of the Higher School of Economics, 9(1), 21-39.

Pierce, J. L., Kostova, T., \& Dirks, K. T. (2003). The state of psychological ownership: Integrating and extending a century of research. Review of General Psychology, 7(1), 84-107. doi:10.1037/10892680.7.1.84

Reiss, S. (2004). Multifaceted nature of intrinsic motivation: The theory of 16 basic desires. Review of General Psychology, 8(3), 179-193. doi:10.1027//1016-9040.6.3.172

Rubinshtein, S. L. (2003). Bytie i soznanie. Chelovek i mir [Being and consciousness. A man and the world]. Saint Petersburg: Piter.

Salmon, W. (1998). Causality and explanation. New York: Oxford University Press.

Shadrikov, V. D. (2013). Psikhologiya deyatel'nosti cheloveka [The psychology of human activity]. Moscow: Institute of Psychology of Russian Academy of Sciences.

Sowden, P. T., Pringle, A., \& Gabora, L. (2015). The shifting sands of creative thinking: Connections to dual process theory. Thinking and Reasoning, 21(1), 40-60. doi:10.1080/13546783.2014.885464

Stern, W. (1998). Differentsial'naya psikhologiya i ee metodicheskie osnozy [Differential psychology and its methodological grounds]. Moscow: Nauka. (Transl. of: Stern, W. (1994). Die differentielle Psychologie in ihren methodischen Grundlagen. Nachdruck der 2. Auflage. Bern [u.a.]: Huber. (in German)).

Sternberg, R. J. (2003). Unify! Monitor on Psychology, 35(2), 5. doi:10.1037/e300052003-002

Tay, L., \& Diener, E. (2011). Needs and subjective well-being around the world. Journal of Personality and Social Psychology, 101(2), 354-365. doi:10.1037/a0023779

Tolochek, V. A. (2013). Problema stilei v psikhologii: istoriko-teoreticheskii analiz [The problem of styles in psychology: Historical-theoretical analysis]. Moscow: Institute of Psychology of Russian Academy of Sciences.

Ushakov, D. V. (2006). Yazyki psikhologii tvorchestva: Yakov Aleksandrovich Ponomarev i ego nauchnaya shkola [Languages of the psychology of creativity: Yakov Aleksandrovich Ponomarev and his scientific school]. In D. V. Ushakov (Ed.), Psikhologiya tvorchestva: shkola Ya.A. Ponomareva [The psychology of creativity: The school of Ya.A. Ponomarev] (pp. 19-142). Moscow: Institute of Psychology of Russian Academy of Sciences. 
Van der Weiden, A., Ruys, K. I., \& Aarts, H. (2013). A matter of matching: How goals and primes affect self-agency experiences. Journal of Experimental Psychology: General, 142(3), 954-966. doi:10.1037/a0030079

Vyatkin, B. A. (2007). Lektsii po psikhologii integral'noi individual'nosti [Lectures on psychology of integral individuality]. Moscow/Voronezh: MPSI/NPO "MODEK".

Vyatkin, B. A. (2008). Lektsii po psikhologii integral'noi individual'nosti cheloveka [Lectures on psychology of integral individuality of man]. Moscow: MPSI.

Vyatkin, B. A. (2015). Integrative study of human individuality. Integrative Perspective in Humanities, 1, 36-44.

Vyatkin, B. A., \& Shchukin, M. P. (2013). Psikhologiya stilei cheloveka [The psychology of human styles]. Perm: Knizhnyi Mir.

Vygotsky, L. S. (1986). Psikhologiya iskusstva [The psychology of art] (3rd ed.). Moscow: Iskusstvo.

Witherington, D. C., \& Crichton, J. A. (2007). Frameworks for understanding emotions and their development: Functionalist and dynamic systems approaches. Emotion, 7(3), 628-637. doi:10.1037/1528-3542.7.3.628

Yurevich, A. V. (2007). Paradigmy v psikhologii [Paradigms in psychology]. Methodology and History of Psychology, 2, 3-17.

Yurevich, A. V. (2012). Estestvennonauchnaya i gumanitarnaya paradigmy v psikhologii [Natural scientific and humanities paradigms in psychology]. In A. L. Zhuravlev, T. V. Kornilova, \& A. V. Yurevich (Eds.), Paradigmy v psikhologii: naukovedcheskii analiz [Paradigms in psychology: Scientific analysis] (pp. 13-33). Moscow: Institute of Psychology of Russian Academy of Sciences.

Zuckerman, M. (2007). Sensation seeking. In M. Zuckerman, Sensation seeking and risky behavior (pp. 3-49). Washington, DC: American Psychological Association.

Leonid Ya. Dorfman - head of Psychology and Pedagogy chair, Perm State Institute of Culture, D.Sc.

E-mail: dorfman07@yandex.ru 